\title{
A Fuzzy-MOP-Based Competence Set Expansion Method for Technology Roadmap Definitions
}

\author{
Chi-Yo Huang ${ }^{1, *}$, Jih-Jeng Huang ${ }^{2}{ }^{\infty}$, You-Ning Chang ${ }^{1}$ and Yen-Chu Lin ${ }^{1}$ \\ 1 Department of Industrial Education, National Taiwan Normal University, Taipei 106, Taiwan; \\ changangela7@gmail.com (Y.-N.C.); sherry84524@gmail.com (Y.-C.L.) \\ 2 Department of Computer Science \& Information Management, SooChow University, Taipei 100, Taiwan; \\ jjhuang@csim.scu.edu.tw \\ * Correspondence: cyhuang66@ntnu.edu.tw; Tel.: +886-2-7749-3357
}

check for

updates

Citation: Huang, C.-Y.; Huang, J.-J.; Chang, Y.-N.; Lin, Y.-C. A

Fuzzy-MOP-Based Competence Set Expansion Method for Technology Roadmap Definitions. Mathematics 2021, 9, 135. https://doi.org/ $10.3390 /$ math 9020135

Received: 31 October 2020

Accepted: 31 December 2020

Published: 10 January 2021

Publisher's Note: MDPI stays neutral with regard to jurisdictional claims in published maps and institutional affiliations.

Copyright: (c) 2021 by the authors. Licensee MDPI, Basel, Switzerland. This article is an open access article distributed under the terms and conditions of the Creative Commons Attribution (CC BY) license (https:// creativecommons.org/licenses/by/ $4.0 /)$.

\begin{abstract}
Technology roadmaps have been widely adopted as an important management tool during the past three decades after their invention by Motorola in the 1980s. Technology roadmapping processes can be integrated with a firm's competence sets and play dominant roles in strategy definitions. Although the issue of how multiple objectives can be dealt with in technology roadmaps by including the uncertainties of the modern management environment is important, it has seldom been addressed. To remedy this, we aim in this research to propose a competence set expansion method based on fuzzy multiple objective programming (FMOP). An empirical study based on the roadmapping of silicon intellectual properties (SIPs) of automotive applications will be used to demonstrate the feasibility of the proposed roadmapping method. In the future, the proposed analytic technique can be integrated with the data mining results of academic research database, patent libraries, etc. The well-verified mathematical programming method can serve as a basis for research and development (R\&D) strategy definitions by managers of high-technology firms as well as policy makers of governments.
\end{abstract}

Keywords: competence set expansion; technology roadmap; fuzzy multiple objective programming (FMOP)

\section{Introduction}

The perception of the technology roadmap was proposed by Robert Galvin, the chief executive officer of Motorola in the 1980s. The original goal of technology roadmapping is to support the strategic planning of technology as well as products [1]. A technology roadmap is an overview of science and technology plans in the form of maps, irrespective of whether the future technologies or products will be for firms or governments. The roadmapping procedure is the establishment of a roadmap, which always includes a multiple-layer illustration of a plan which links technology and products with market opportunities [2].

The general technology roadmap is a chart with date or time data; the chart usually consists of numerous layers of technologies and products, which typically include both commercial and technological aspects. A technology roadmap visualizes the development of markets, products, and technologies to be explored as well as the connections or relationships between the various aspects [3]. A technology roadmap also reveals how a technology can be fitted with product and service developments, business strategies, and market opportunities [3]. Hence, technology roadmaps have been widely adopted in numerous sectors, including the high technology, manufacturing, and service sectors, at the levels of firms, industries, and governments [4].

Prahalad and Hamel [5] regarded an organization's competence as the capacity to learn how to organize various manufacturing techniques and integrate technologies. The workforce capabilities, incorporated in teams and linked by organizational structures and practices, are the components of competence [6]. Competence is regarded as the foundation 
of competitiveness, allowing firms to offer products and services that are beneficial to customers. Meanwhile, competences enable firms to innovate and, thus, to generate novel products and services so that they can adapt to the fast-changing circumstances more quickly than their competitors [6]. According to Yu [7,8], for each decision-making problem (e.g., a strategy definition), a competence set includes the ideas, knowledge, information, and skills with which satisfactory solutions can be found. Therefore, based on the work of Van Kleef and Roome [6], an innovation competence set is a set that contains the innovation capabilities that are relevant to systems thinking, learning, combining, integrating, thinking inventively, networking, and coalition building. Thus, how these competences can be gained by an organization is a matter of great importance.

Normally, these competences cannot be gained simultaneously because of the limited availability of resources. Furthermore, numerous objectives should be considered concurrently when a firm wants to develop the required competences. Moreover, the fuzziness and uncertainties associated with decision-making problems should be addressed. For example, the turnover of key personnel or the unavailability of critical components can disturb the originally well-scheduled plan of development. During the past several decades, many scholars (e.g., $[9,10])$ have proposed quantitative or qualitative analytic frameworks for solving technology roadmapping problems. However, no one has, to our knowledge, proposed an analytic framework based on fuzzy multiple objective programming (FMOP). Nevertheless, these problems are important and occur in many practical situations faced by, for example, planners of governments or marketers of high-technology firms.

To solve roadmapping problems and fill in the research gap, we would like to propose a competence set expansion framework based on FMOP. First, the competences necessary for achieving the future strategic objectives of a given organization will be determined based on opinions provided by experts using the modified Delphi method. Then, by considering different objectives, the fuzzy costs required for developing a given competence from another competence will be defined by the experts. The minimum expansion paths for achieving the competences can then be obtained based on the parametric approach to fuzzy linear programming proposed in [11,12]. At last, the time slot for beginning the research and development $(R \& D)$ of a given competence will be identified by the experts. A technology roadmap based on the FMOP technique can then be derived accordingly. An empirical study for the roadmapping of silicon intellectual properties (SIPs) for automotive applications will be employed to verify the feasibility of the proposed framework. For readers' convenience, a list of abbreviations and symbols introduced in this work are listed in Table 1.

This work integrates the concepts of both competence set expansion and the FMOP into the technology roadmapping framework. The integration framework has seldom been applied to real-world strategic planning problems in general or to the technology roadmapping problem specifically. Many uncertainties exist in the development of new products, services, and techniques. The introduction of the concept of fuzziness is essential. Scholars and practitioners can use the analytic framework developed here to solve the uncertainties in and fuzziness of their roadmapping problems.

The paper is organized as follows. The related literature regarding technology roadmapping and competence set expansion will be reviewed in Section 2. The FMOPbased competence set expansion technique will be introduced in Section 3. Section 4 explains the procedure of the empirical study. Section 5 concludes the work and provides future research possibilities. 
Table 1. Notations and abbreviations.

\begin{tabular}{clcl}
\hline Notations & \multicolumn{1}{c}{ Descriptions } & Notations & \multicolumn{1}{c}{ Descriptions } \\
\hline$A$ & An $(m \times n)$ matrix & $\operatorname{Tr}(E)$ & True competence set \\
$b$ & An $m$-vector & $\operatorname{Tr}^{*}(E)$ & $\begin{array}{l}\text { Perceived competence set } \\
\text { Competence } i\end{array}$ \\
$c_{i j}$ & An $n$-vector & $x_{i}$ & The cost of acquiring $x_{i}$ from $x_{j}$ \\
$\widetilde{c}_{i, j}^{(k)}$ & Fuzzy cost from $x_{i}$ to $x_{j}$ under $O_{k}$ & $u_{i}$ & Subsidiary variable \\
$C S^{*}(E, t)$ & Time variant competence set & $\mu$ & The ith objective under $O_{k}$ \\
$E$ & A given decision problem & $\mu^{-1}$ & Membership functions \\
HD & Habitual domain & & functions membership \\
$O_{k}$ & The objective $k$ & & \\
$p$ & A parameter of the model & & Abbreviations \\
$S k(E)$ & skill set & FLS & Fuzzy linear system \\
$S k^{*}(E)$ & Perceived acquired skill set & FMOP & Fuzzy MOP \\
$t$ & time & MOP & $\begin{array}{l}\text { Multiple objective } \\
\text { programming }\end{array}$ \\
$T$ & Truly required competence set & R\&D & Research and development \\
$t_{k}$ & Specific SIP $k$ & SIP & Silicon intellectual \\
& & & properties \\
\hline
\end{tabular}

\section{Literature Review}

In this section, previous studies on competence sets, competence set expansion, technology roadmaps, 2.3 MOP, and FMOP will be reviewed. The reviewed literature will serve as the basis for developing the FMOP-based analytic framework in Section 3.

\subsection{Competence Sets}

Everyone has familiar ways to respond to external stimuli. These response patterns are referred to as conditional or programmed behavioral patterns. The gathering of these routine methods of perceiving, thinking, responding, and acting, as well as their development, dynamics, and roots in experience and knowledge, is called a person's domain of habits, or habitual domain. This domain strongly influences people's behaviors as well as decision-making processes. Four subconcepts of habitual domains exist: potential domains, actual domains, activation propensity, and reachable domains [13]. Grounded on these habitual domains, Yu and Zhang [14,15] defined the concept of competence set analysis, which aims to solve specific decision-making problems by obtaining the required ideas, information, skills, and knowledge. A competence set is a group of skills and knowledge areas that can be adopted to solve a specific problem [16]. Numerous managerial, social, economic, and industrial decision-making problems require specific competence sets to solve them effectively [17]. Competence set analysis aims to recognize a true competence set, the competence set of a decision-maker, and an efficient path for expanding the competences and for making appropriate decisions [18]. Competence sets, as projections of habitual domains, can be dynamically altered as novel skills, resources, information, or situations become available [19]. In general, a competence is time-variant [17].

In the real world, most decision-making problems are based on multiple criteria. Practical examples of competence sets can be found everywhere in our daily life. Decision-makers can solve a decision-making problem confidently and comfortably if they have already acquired the required competence set for the specific problem [20]. To intensify the effectiveness of working out solutions for decision-making problems, the perceiving, acquiring, and mastering of the required competence sets serve dominant roles [20]. When decisionmakers have gained the required competence sets and are competent or skilled in these competences, decision-making will be comfortable and confident, or else decision-makers should obtain the necessary competence sets to work out solutions for the problem. For the purpose of obtaining a required competence set to resolve a decision-making problem, suitable processes for learning the required competences, so-called competence set expansion, 
are essential. A decision-making problem can be defined as the process of transforming a given competence set into another competence set. A decision-making problem can be difficult to solve at the time when decision-makers do not know clearly what the true competence sets, the so-called target competence sets, are and what approaches they must use to change their competence sets to obtain the target competence sets [21].

Given a decision-making problem, different decision-makers may see the required competence set in different or alternative ways. Indeed, a competence set for a specific decision-making problem is a habitual domain that is projected onto the problem. Note that competence sets can be time-variant. For a given decision-making problem $E$, four basic elements exist [22]. Based on Shi and Yu [23], the four basic elements (see Figure 1) can be defined below: (1) The true competence set $(\operatorname{Tr}(E))$ includes knowledge, skills, information, and resources which are indispensable for correctly resolving decision-making problem $E$. (2) The perceived competence set $(\operatorname{Tr} *(E))$ is the accurate competence set as recognized by the decision-maker. (3) The skill set $(S k(E))$ contains ideas, knowledge, skills, information, and resources that have exactly been obtained by the decision-maker. (4) The recognized acquired skill set $(S k *(E))$ is the obtained skill set as obtained by the decision-maker.

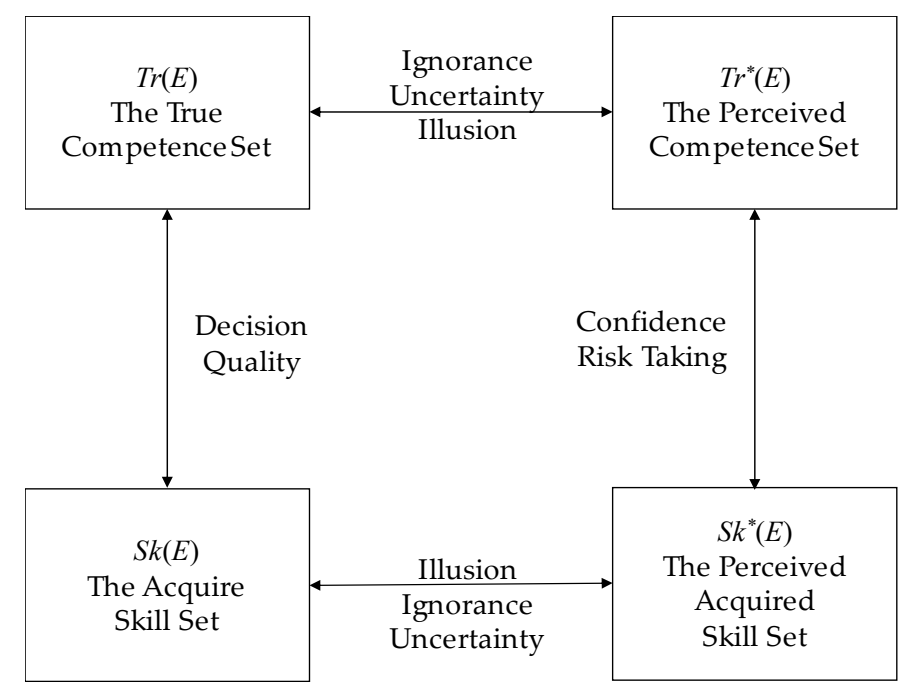

Figure 1. The interrelationships among the four elements of a competence set. Source: Shi and Yu [23].

Based on the interrelationship between the acquired competence set and the actually needed competence set, decision problems can usually be categorized into four classes [23]: (1) routine problems, which are already well-known to the decision-maker and for which the decision-maker has already obtained the competence set that is required for successfully solving them; (2) mixed routine problems, which are decision-making problems that consist of numerous routine subproblems; (3) fuzzy problems, for which the decision-maker only vaguely knows the truly needed competence set and for which the decision-maker has not yet mastered the competences required for successfully solving them; and (4) challenging problems, for which the truly needed competence set is unknown or only partially known to the decision-maker.

Recently, based on the theory of habitual domain, Larbani and Yu [24,25] further proposed the concept of changeable space, which suggests that parameters in real-world decision-making problems can be variable over time. According to Labani and Yu [24,25], conventional decision-making problem models are unique changeable spaces where almost all the decision parameters are invariant. Here, the concept of competence set will be adopted to solve decision-making problems in changeable spaces. The competence set of a specific decision problem, $E$, denoted by $C S^{*}(E, t)$, is defined as the set of ideas, concepts, knowledge, expertise, etc., being required for deriving solutions. The variable $t$ in $C S^{*}(E, t)$ is used to emphasize those parameters that are time-variant. 


\subsection{Technology Roadmaps}

Robert Galvin, the chief executive officer of Motorola in the 1980s, defined the technology roadmap as "an extended look at the future of a chosen field of inquiry composed from the collective knowledge and imagination of the brightest drives of change in that field" [26-29]. Kostoff and Schaller [30] described the technology roadmap as the illustration of the future science and technology landscape being agreed with and available to decision-makers. The technology roadmap provides a way to identify, evaluate, and select strategic alternatives that can be adopted to achieve a necessary scientific or technological objective $[1,30]$. The technology roadmap illustrates the plans of science and technology development as maps; roadmapping is the procedure for developing the roadmap. The technology roadmap always contains a multilayer illustration of a plan that links technology and products with market opportunities [2]. Therefore, technology roadmaps have been regarded as one of the most useful tools for managing research and development (R\&D) plans and for pointing out the future plan of technology development at the firm, industrial, governmental as well as organizational levels [31].

Although numerous definitions of technology roadmaps are available, technology roadmaps could also be defined with reference to the roadmapping process-the set of activities which are needed for defining and developing a roadmap. Roadmapping has been described as a process integrationing business and technology as well as facilitating the definitions of both short-term and long-term technological strategies according to the mutual interaction between products and technologies over time [32]. Yoon et al. [33] presented skills of summarizing, information extracting, clustering and navigating to organize technological information being used by technology roadmapping processes. Lee et al. [34] described the roadmapping process as a market-driven process for planning technology. The process which can fulfill customer needs [34-36] can also serve as a tool of communication or knowledge management, which is able to backing the requirements of strategic decision-making activities [37], and an integrated approach that can develop strategies with which the scientific or technological considerations can be summarized to provide valuable input to product and business planning [38].

In general, the concept of technology roadmapping can be identified in two distinct methods: A somewhat strict definition describes only roadmapping activities which emphasis on technologies being related to products or processes [39]. Based on this explanation, the roadmaps of product, project, and function are equal to technology roadmaps [39]. The concept of technology roadmapping can also be interpreted less precisely, including all roadmapping procedures or activities about technologies, products, processes, functions, market agents, competences, projects, etc. [39].

The technology roadmap has been regarded as a noticeable tool for the strategic planning of technology for a long time [40,41]. Concerning customer needs, technology roadmaps are adopted to support generating novel ideas for developing products, forecasting trends of technology development, and recognizing promising technologies [42,43]. Technology roadmaps allow firms to perform R\&D activities systematically, mapping clear plans regarding to technologies to be developed, the appropriate time to develop those technologies, and in what way those technologies can be developed. Science and technology roadmaps have broadly been adopted by firms, governments, universities, and research institutes to illustrate the structural relationships among science, technology, products, and applications [30]. The technology roadmap has long been thought as a practical tool for connecting business to technologies. Consequently, forming the relationships among market, product, and technology elements is an indispensable task of establishing effective technology roadmaps [44]. Therefore, the technology roadmap has lured the attention of a growing number of researchers and industry managers. Meanwhile, the technology roadmap has been adapted in numerous industrial sectors and organizations [45]. Moreover, various scholars regard a technology roadmap as a visualization tool for the strategic management of technology. Although numerous definitions are available for roadmaps, the main characteristics and benefits are mainly related to visualizing and communicat- 
ing [46]. Many industry managers and scholars demonstrate or brief such technological information to accomplish numerous advantages. The work by Trappey, Trappey, Fan, Hsu, $\mathrm{Li}$ and Lee [47] is a typical example; in that work, they proposed a roadmapping method for visualizing the patent allocations and developments related to the logistic services at each level.

The general roadmap is a chart based on time. The generic map consists of numerous layers that usually contain perspectives of business and technology. The roadmap allows exploring the development of markets, products, applications, and technologies by linking the numerous viewpoints [3]. The roadmap demonstrate how technology can be associated with product and service developments, strategy of firms, and business opportunities [3].

Many efforts have been made to adopt numerous techniques by integrating the roadmapping procedure so as to improve or advance the method [34]. Bray and Garcia proposed a three-phase approach: initiation, roadmap development, and next-stage activities [48]. Groenveld [32] proposed a seven-stage roadmapping procedure. The T-Plan being proposed helps the immediate launch of technology roadmaps in a three-stage process: planning, roadmapping, and rollout [49]. A modified T-Plan procedure with five major modules was also proposed [50]. Lee and Park [41] proposed an analytic framework for adapting the roadmapping techniques based on their particular purposes, recommending eight styles of roadmaps. The shared characteristic of those techniques is the intention to enhance decisions regarding the prioritization of technologies to be developed [34]. For example, analytic techniques like the analytic hierarchy process being proposed by Saaty [38] and portfolio analysis [51] have been integrated into roadmapping processes. Furthermore, the quality function deployment as well as the GRID (decision matrix) analysis had been adapted to establishing interrelationships among markets, products, and technologies [34,51-54].

These roadmapping procedures usually contain a key stage: identifying the interrelationship among layers. As the technology roadmap is a multilayer illustration containing market, product, and technology layers, identifying interrelationships among layers is vital for defining the "when and how" strategy. One of the most common methods is a chart based on time, which was first suggested by the European Industrial Research Management Association [55], that includes the market, product, and technology layers. Consequently, a roadmap allows the development of these three layers to be explored. Moreover, a roadmap also permits the linkages among the three layers to be emphasizedi.e., between market drivers and products or between products and technologies $[56,57]$. Kostoff and Schaller [30] noted the requirement for deriving functional relationships in technology roadmaps. Owing to the inherent uncertainties and growing requirements in big programs, the configuration of the technology roadmap must be as flexible as possible to integrate the dynamics. This emphasizes the significance of linked functional relationships that broadcast changes at any node of the technology roadmap to every layer of the technology roadmap [30]. The task of identifying interrelationships among layers, however, is reliant on generally on opinions being provided by experts $[30,58]$. Recently, owing to the emergence of big data analytics, a proactive procedure of including the data is gradually becoming vital.

Technology roadmaps have already been broadly adopted in numerous sectors, such as the high technology, information technology, financial services, and manufacturing sectors, and in various fields at the product, technology, firm, industrial, and governmental levels [4]. A study of British manufacturing firms in 2001 indicated that 10\% of medium to large firms had applied technology roadmaps, with a majority $(80 \%)$ of those firms had adopted the roadmapping approach more than once or frequently, with exponential growth in interest in the roadmapping methods since the early 1990s [59].

\subsection{MOP and FMOP}

Multiple objective decision-making (MODM) theories and methods were developed to solve optimal decision-making problems, where numerous objectives should be achieved 
at the same time. Such problems usually consist of a set of conflicting objectives as well as a set of well-defined constraints. Consequently, adopting mathematical programming techniques or methods to solve optimization problems is straightforward [60].

Since Kuhn and Tucker [61] proposed to solve multiple objective decision-making problems by adopting the vector optimization concept, and Yu [62] suggested the compromise solution method to resolve the MODM problems, numerous scholars dedicated themselves to develop and/or applying the MODM methods. Furthermore, the theoretical frameworks have been expanded from simple MOP techniques to multilevel MOP and multistage MOP techniques to solve complex problems in the real world [60].

However, traditional MODM methods tend to overlook the uncertainties in decisionmaking problems. Thus, the fuzzy concepts being proposed by Bellman and Zadeh [63] were introduced into MODM methods for handling uncertainties or vagueness. Numerous distinguished scholars, such as Hwang and Yoon [64], Zimmermann [65], Sakawa [66], Lee and Li [67], and Tzeng and Huang [60], have dedicated themselves to the study of fuzzy multiple objective decision-making (FMODM) methods and/or applications that consider objectives as well as constraints as fuzzy sets, which are based on the individual linear membership functions. A decision set is defined by the intersection of all fuzzy sets and the relevant hard constraints.

Recently, various scholars have tried to advance the concepts or methods of MODM and FMODM. The trend of MODM has evolved gradually, from a win-lose strategy to a win-win strategy, which suggests that firms can create added value and achieve better parameters through the use of flexible resources and by expanding competence sets [60]. Furthermore, scholars have tried to advance the methods of MODM and FMODM by proposing novel approaches. Atteya [68] used rough set theory to solve MOP problems. Holzmann and Smith [69] solved the discrete MOP problems by adopting modified augmented weight Tchebychev scalarizations. Botte and Schöbel [70] introduced multiscenario efficiency for robust MOP methods. Chung et al. [71] proposed a new multichoice goal programming model for solving FMOP problems where ideal and anti-ideal solutions are not required anymore. Roy et al. [72] proposed a new memetic genetic algorithm for resolving the traveling salesman problem based on the multiparent crossover technique. Biswas and Pal [73] proposed a fuzzy goal programming technique to resolve the congestion management problem by adopting a genetic algorithm. Ganguly [74] proposed a multiobjective distributed generation penetration planning with load model using particle swarm optimization. Borovička [75] proposed a new complex FMOP procedure for a portfolio-making problem under uncertain conditions.

Meanwhile, numerous scholars have tried to apply novel MODM and FMODM methods to various applications. For example, Koronakos et al. [76] formulated the assessment of the Better Life Index as a multiple objective programming (MOP) problem, which facilitates the implementation of distinct concepts to derive different aggregation schemes. Tavana et al. [77] proposed a fuzzy multiobjective multiperiod network DEA model for measuring efficiency of oil refineries. Kouaissah and Hocine [78] optimized sustainable and renewable energy portfolios using a fuzzy interval goal programming approach.

\subsection{Research Gaps}

In summary, the literature review revealed several research gaps. First, conventional competence set expansion researches have not been integrated with the MOP techniques. However, the competence set expansion problem for business strategy definitions is an MODM problem by nature. Second, the technology roadmapping problem is a strategy definition problem by nature. However, few scholars tried to integrate the roadmapping problem with the strategic planning frameworks, not to mention the competence set expansion technique. Third, existing methods for roadmapping seldom consider the fuzziness of the parameters. However, many uncertainties exist in the development of new products, services, and techniques. Thus, the introduction of the concept of fuzziness is essential. Fourth, the competence set expansion problem solved by the FMOP technique is useful 
for real-world applications. However, empirical studies that analyze the competence set expansion problem solved by the FMOP are still rare. Consequently, the proposed FMOPbased competence set expansion method for technology roadmap definitions will be useful to address the traditional research gaps in strategy definitions, technology roadmapping, and applications of the FMOP-based competence set expansion in real-world management problems. Thus, the analytic framework and empirical study results will be meaningful for scholars and practitioners of technology management.

\section{Research Methods}

The overall competence set expansion process should include the following steps at least: (1) a detailed review of the most up-to-date status of technology, (2) a forecast of the technology required in the prediction period, (3) a comparison between the current competence set of the firm and the competence set to be expanded, and (4) a decision on the methods for expanding the competence set as well as the definitions of strategies for achieving the above-mentioned expansion. The optimal path for expanding the competence set aims to analyze how a decision-maker can effectively expand to the actually needed competence set from the already obtained competence set for solving a decision problem. Many researchers point out that competence set analysis is vital for improving a firm's collaboration strategy, innovation capabilities, operational efficiency, and supply chain performance [16,79-83]. The applications of competence set expansion include the management of production and operations, information, marketing, project, strategic alliance [20], and supply chains [16]. In this work, a novel analytic framework will be proposed to define a method based on the concept of competence set expansion. First, the modified Delphi method will be introduced. The technology required by a specific firm in the next five years will be agreed upon by the experts. Furthermore, the objectives for expanding the competences will also be agreed upon by the experts. Then, the fuzzy multiple objective optimal expansion process for competence sets will be introduced. Finally, the time slot for introducing specific techniques will be defined. A technology roadmap will thus be defined. Next, the modified Delphi method will be introduced in Section 3.1. Then, the competence set expansion process will be introduced in Section 3.2. The parametric approach to fuzzy linear programming will be introduced in Section 3.3. The FMOP-based competence set expansion programming technique will be introduced in Section 3.4. The analytic process is illustrated below in Figure 2 for the readers' better understanding of how the competence set expansion process is connected to the technology roadmap.
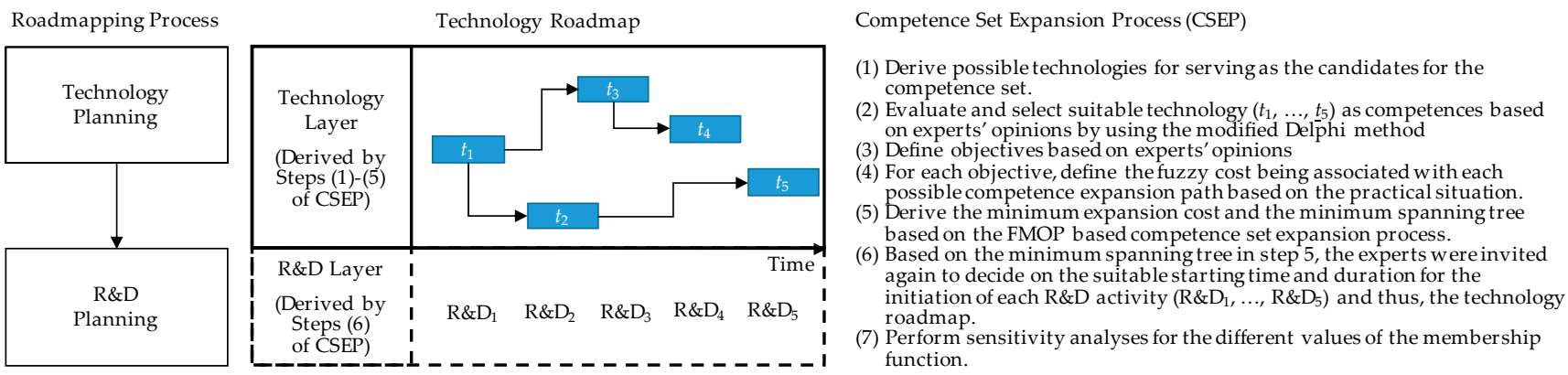

Figure 2. The roadmapping process, technology roadmap, and the competence set expansion process. Source: Adapted from [84].

\subsection{Modified Delphi Method}

The Delphi method was proposed by Dalkey and Helmer [85] in 1963 to summarize the opinions being provided by respondents on particular issues, topics, or problems under investigation. Owing to the tedious and complicated processes being involved in adopting and manipulating the Delphi method, Murry and Hammons [86] later modified the conventional Delphi method in 1995 by substituting the open questionnaires with the 
ones which have been carefully reviewed and selected based on the results of reviewing literature review or summarizing experts' opinions, etc. The main advantages of the modified Delphi method include an easily-reached consensus [87], a high percentage of responses, solid foundation of the questionnaires, a reduction in probable biases or errors, assurance of the privacy of the respondents, and provisions of the controlled results to those who participated in the surveys.

\subsection{Competence Set Expansion}

The optimal competence set expansion path can be derived based on the following mathematical programming model proposed by Tzeng and Huang [60]:

$$
\begin{aligned}
& \min z=\sum c_{i j} x_{i j} \\
& \text { s.t. } \sum_{i=0}^{n} x_{i j}=1, j=1,2, \ldots, n, \\
& u_{i}-u_{j}+(n+1) x_{i j} \leq n, 1 \leq i, j \leq n, i \neq j, \forall_{i j}, \\
& u_{i}, u_{j} \in\{0,1, \ldots, n,\},
\end{aligned}
$$

where $z$ denotes the objective function, $c_{i j}=c\left(x_{i}, x_{j}\right)$ denotes the cost of obtaining the competence $x_{i}$ from $x_{j}, u_{i}$ denotes the subsidiary variable, and $n$ is the number of competences [60].

Though numerous scholars extended the method of competence set expansions by considering additional situations, such as asymmetric acquiring costs [88] and group decisions, their papers address only one-stage and one-objective situations. However, we can extend competence sets to consider multistage problems, multi-objective problems, or fuzzy environments for more complex applications [60].

Numerous methods or techniques-for example, the minimum spanning tree, the mathematical programming method, and deduction graphs-have been recommended to derive the optimal path for expanding competence sets. As modified from [60], the optimal expansion process from the existing or acquired competence set to the true competence set can be described as follows.

Let $H D=S K \cup T$, where $H D$ means all the related skills being required to resolve a specific problem. Furthermore, $S K$ represents the already obtained competence set, and $T$ represents the truly required competence set. Consequently, the optimal expansion process can be represented as in Figure 3.

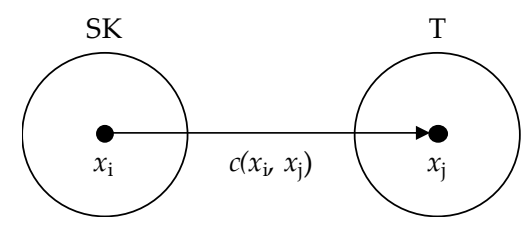

Figure 3. The optimal expansion process of a competence set.

The MOP-based optimal expansion process of competence sets can be obtained by transforming the routing method being proposed by Shi and Yu [88] to choose the optimal expansion process by considering $m$ objectives based on the following mathematical programming model [60]:

$$
\begin{aligned}
& \min z_{k}=\sum_{i=0}^{n} c_{i j} x_{i j}, j=1,2, \cdots, n, \forall k=1, \ldots, m \\
& \text { s.t. } \sum_{i=0}^{n} x_{i j}=1, j=1,2, \ldots, n, \\
& u_{i}-u_{j}+(n+1) x_{i j} \leq n, \\
& u_{i}, u_{j} \in\{0,1, \cdots, n\}, i \neq j, \forall i, j .
\end{aligned}
$$

where $z_{k}$ denotes the $k$ th objective function. 


\subsection{Fuzzy Parametric Programming}

A typical linear programming model can be expressed as follows:

$$
\begin{aligned}
& \max z=c^{\prime} x, \\
& \text { s.t. } x \in X=\{x \mid-A x \leq b, x \geq 0\},
\end{aligned}
$$

where $\boldsymbol{c}$ is an $n$-vector, $\boldsymbol{A}$ is an $(m \times n)$-matrix, and $\boldsymbol{b}$ is an $m$-vector. In real-world decisionmaking problems, vagueness or uncertainties always exist in the parameters. Therefore, assume that the management of firms or planners of governments can define the intervals $\left[c^{0}, c^{1}\right],\left[A^{0}, A^{1}\right]$, and $\left[b^{0}, b^{1}\right]$ for the possible values of the parameters. The lower and upper bounds of the intervals represent the lowest and highest possible values of the parameters.

The fuzzy parametric programming technique proposed by Carlsson and Korhonen [89] aims to derive an optimal "in-between" compromise as a function of the grades of imprecision in the parameters. Let $\mu$ denote the membership functions. The subscripts $c, A$, and $\boldsymbol{b}$ are then used to specify with which parameters the membership functions are associated $\left(\mu_{c}, \mu_{A}, \mu_{b}\right)$. We will use the subscript $p$ to refer to a parameter of the model Equation (3). Let us define the linear membership function as

$$
\mu_{p}=\left[\left(p-p^{1}\right) /\left(p^{0}-p^{1}\right)\right],
$$

where $p \in\left[p^{0}, p^{1}\right]$, with $\mu_{p}=1$, if $p \leq p_{0}$, and $\mu_{p}=0$, if $p \geq p_{1}$. Therefore, the parameter $p$ can be written as follows:

$$
p=\mu_{p}\left(p^{0}-p^{1}\right)+p^{1} .
$$

Then we can rewrite our model Equation (3) into a parametric form:

$$
\begin{aligned}
& \max z=\left(\boldsymbol{c}^{1}+\Delta \boldsymbol{c}\left(\mu_{c}\right)\right)^{\prime} \boldsymbol{x}, \\
& \text { s.t. }-A^{1}+\Delta \boldsymbol{A}\left(\mu_{A}\right) \boldsymbol{x} \leq \boldsymbol{b}^{1}+\Delta \boldsymbol{b}\left(\mu_{\boldsymbol{b}}\right), \\
& x \geq 0,
\end{aligned}
$$

since $\Delta p=\left(p^{0}-p^{1}\right)$ in the linear case. Because $\mu_{c}=\mu_{A}=\mu_{\boldsymbol{b}}$, we can omit the indices. If all the membership functions are linear, Equation (3) can be formulated as

$$
\begin{aligned}
& \max z=\left(\boldsymbol{c}^{1}+\mu\left(\boldsymbol{c}^{0}-\boldsymbol{c}^{1}\right)\right)^{\prime} \boldsymbol{x}, \\
& \text { s.t. }-\left(\boldsymbol{A}^{1}+\mu\left(\boldsymbol{A}^{0}-\boldsymbol{A}^{1}\right)\right) \boldsymbol{x} \leq \boldsymbol{b}^{1}+\mu\left(\boldsymbol{b}^{0}-\boldsymbol{b}^{1}\right), \\
& \boldsymbol{x} \geq \mathbf{0} .
\end{aligned}
$$

In each case, a linear parametric programming problem will be solved. In the linear case, the parameter $\mu: 0 \rightarrow 1$. If the membership functions are different in form, the optimization problem cannot be solved using the linear parametric programming method. However, the problem can easily be solved by performing a sensitivity analysis with different values of the membership functions, followed by solving the corresponding linear programming problem.

\subsection{Competence Set Expansion Based on FMOP}

In order to formulate fuzzy multiple objective competence set expansion, the fuzzy parametric mathematical programming model introduced in Section 3.3 is employed here. Based on [12], the fuzzy programming problem can be represented as follows:

$$
\begin{gathered}
\max \widetilde{z}=\sum \widetilde{c}_{i} \widetilde{x}_{i} \\
\text { s.t. } \widetilde{X}=\left\{(x, \mu(x)) \mid(\tilde{A} \boldsymbol{x})_{i} \leq \tilde{\boldsymbol{b}}_{i}, \forall i, x \geq 0, \mu(x) \in[0,1]\right\},
\end{gathered}
$$


where $\mu(x)$ means the membership function of $x$. By setting the adequate membership function and $\alpha-c u t$, Equation (7) can be transformed into Equation (8) to solve the fuzzy programming problem.

$$
\begin{aligned}
& \max \widetilde{z}=\sum_{j=1}^{n} \mu_{\widetilde{c}_{j}}^{-1}(\alpha) x_{j}, \\
& \text { s.t. } \sum_{j=1}^{n} \mu_{\widetilde{a}_{i j}}^{-1}(\alpha) x_{j} \leq \sum_{j=1}^{n} \mu_{\widetilde{b}_{j}}^{-1}(\alpha), \forall i=1, \ldots, m, \\
& x_{j} \geq 0, \forall j=1, \ldots, n,
\end{aligned}
$$

where $\mu_{\widetilde{c}_{j}}^{-1}(\alpha), \mu_{\widetilde{a}_{i j}}^{-1}(\alpha)$, and $\mu_{\widetilde{b}_{j}}^{-1}$ represent the intervals introduced in Section 3.3: $\left[c_{j}^{0}, c_{j}^{1}\right]$, $\left[a_{i j}^{0}, a_{i j}^{1}\right]$, and $\left[b_{j}^{0}, b_{j}^{1}\right]$, corresponding to $\alpha$. Then, the FMOP-based expansion processes for competence sets can be derived.

Suppose that $m$ objectives (e.g., quality, time-to-market, performance, differentiation) should be achieved by competence set expansion. Then, by assuming equal importance of the objectives and competences, we can derive the expansion paths based on the following mathematical programming model. For the $k$ th objective $(k=1, \cdots, m$,$) ,$

$$
\begin{gathered}
\min / \max \widetilde{z}_{k, 1}=\sum \mu_{\widetilde{c}_{k, 1 i j}}^{-1}(\alpha) x_{1_{i j}} \\
\min / \max \widetilde{z}_{k, 2}=\sum \mu_{\widetilde{c}_{k 2, i j}}^{-1}(\alpha) x_{2_{i j}} \\
\vdots \\
\min / \max \widetilde{z}_{k, n}=\sum \mu_{\widetilde{c}_{k, m i j}}^{-1}(\alpha) x_{n_{i j}} \\
\text { s.t. } \sum_{i=0}^{n} x_{i j}=1, j=1,2, \ldots, n, \\
u_{i}-u_{j}+(n+1) x_{i j} \leq n, 1 \leq i, j \leq n, i \neq j, \\
\forall x_{i j}, u_{i} \in\{0,1, \ldots n\},
\end{gathered}
$$

where $c_{i j}=c\left(x_{i}, x_{j}\right)$ means the cost for obtaining $x_{j}$ from $x_{i}$ and $u_{i}$ means the subsidiary variable. As stated earlier, since some criteria are intangible and conflict with each other, a Pareto solution can be derived using multiple objective evolutionary algorithms. Then, decision-makers are able to choose the final optimal expansion process according to their preferences [60].

\section{Empirical Study}

In this section, an empirical study modified from a real technology evaluation and selection case will be adopted to verify the feasibility of the proposed programming technique. For an integrated circuit design service firm that aims to develop SIPs targeting an application-specific integrated circuit for emerging artificial intelligence markets (e.g., unmanned vehicles), a technology roadmap for the R\&D plans for the next five years should be developed. First, the modified Delphi method will be used to determine the techniques required to fulfill the future demands. Then, from the three objectives to be fulfilled - time-to-market, functional safety, and reliability-the costs for expanding from one technique to another will be surveyed by questionnaires. Finally, the paths for competence expansion will be derived by using the FMOP-based programming technique introduced in Section 3.4. After that, the time frame will be added based on experts opinions.

\subsection{Selection of the Technology by the Modified Delphi Method}

In order to investigate and refine the feasibility of criteria regarding technology selection, the modified Delphi method is applied to summarize the appropriate SIPs. Based on the existing solutions of market leaders (e.g., the advanced driver assistance systems by Synopsys) and the survey results of the marketers, 15 SIPs were selected: multiport LPDDR4 controller $\left(t_{1}\right)$, Ethernet QoS controller $\left(t_{2}\right)$, MIPI I3C controller $\left(t_{3}\right)$, UFS host 
controller IP $\left(t_{4}\right)$, HDMI controller $\left(t_{5}\right)$, vision processors $\left(t_{6}\right)$, PCI express controller $\left(t_{7}\right)$, DDR controller $\left(t_{8}\right)$, AMBA interface controller $\left(t_{9}\right)$, HDMI controller $\left(t_{10}\right)$, CAN controller $\left(t_{11}\right)$, DSP $\left(t_{12}\right)$, peripheral sensor interface $\left(t_{13}\right)$, motor controller $\left(t_{14}\right)$, and GPIO $\left(t_{15}\right)$.

Based on the definition of the modified Delphi method, the $75 \%$ ratio was defined as the minimum percentage of agreement on any particular criterion. Table 2 shows the number of experts agreeing on the chosen technology. For the remaining criteria, the ratios exceeded $75 \%$. Thus, these requirements are recognized as suitable for predicting the technology selection.

Table 2. Experts' backgrounds.

\begin{tabular}{ccc}
\hline Education & Industry & Position \\
\hline Master & ITS & General manager \\
Master & IC design service & Vice president \\
Master & IC design service & Manager \\
Master & IC design service & Manager \\
Ph.D. & Universities or research & Professor \\
Master & institutes & Vice president \\
Master & Unmanned vehicle & Director \\
\hline
\end{tabular}

\subsection{Expanding Technology Competence Sets}

The competence set expansion method helps decision-makers obtain the most efficient solution from the competence sets and solve the problems. In this study, as described in the previous sections, we received the industry's competence set for a parking lot's energy-saving illumination system. We employed the competence set expansion method to help the design service firm to obtain the optimal and the most efficient expansion route toward achieving its aspirational level of competence.

Let $S k(E)=\left\{x_{0}\right\}$ be the competence set that design service firm $X$ has already gained and let $\operatorname{Tr}(E)=\left\{x_{0}, x_{1}, \ldots, x_{15}\right\}$ be the competence set that the firm needs to achieve its aspirational level. Based on the questionnaires collected from the managers and engineers familiar with the design service providers, the costs for expanding the competence set under the three objectives-time-to-market $\left(O_{1}\right)$, functional safety $\left(O_{2}\right)$, and reliability $\left(\mathrm{O}_{3}\right)$-can be derived. The development costs of each technology, $x_{i}$ to $x_{j}$, are represented as a fuzzy interval number. The cost function is defined as the cost needed for reaching one technology from another one.

Based on the fuzzy costs shown in Tables A1-A3 of Appendix A, we can derive the optimal multi-criteria expansion process as the following mathematical programming:

$$
\begin{aligned}
& \min \widetilde{z}_{0}^{(1)}=\sum \widetilde{c}_{0, j}^{(1)} x_{0, j} \\
& \min \widetilde{z}_{1}^{(1)}=\sum \widetilde{c}_{1, j}^{(1)} x_{1, j} \\
& \vdots \\
& \min \widetilde{z}_{15}^{(1)}=\sum \widetilde{c}_{15, j}^{(1)} x_{15, j} \\
& \min \widetilde{z}_{0}^{(2)}=\sum \widetilde{c}_{0, j}^{(2)} x_{0, j} \\
& \min \widetilde{z}_{1}^{(2)}=\sum \widetilde{c}_{1, j}^{(2)} x_{1, j} \\
& \vdots \\
& \min \widetilde{z}_{15}^{(2)}=\sum \widetilde{c}_{15, j}^{(2)} x_{15, j} \\
& \min \widetilde{z}_{0}^{(3)}=\sum \widetilde{c}_{0, j}^{(3)} x_{0, j} \\
& \min \widetilde{z}_{1}^{(3)}=\sum \widetilde{c}_{1, j}^{(3)} x_{1, j} \\
& \vdots \\
& \min \widetilde{z}_{15}^{(3)}=\sum \widetilde{c}_{15, j}^{(3)} x_{15, j} \\
& \operatorname{s.t.} \sum_{i=0}^{15} x_{i, j}=1, j=1,2,3, \ldots, 15 \\
& u_{i}-u_{j}+(15+1) x_{i, j} \leq 15, \quad 1 \leq i, j \leq 15, \quad i \neq j \\
& \forall x_{i, j}, u_{i} \in\{0,1, \ldots, 15\},
\end{aligned}
$$


where $\widetilde{z}_{i}^{(k)}$ denotes the $i$ th fuzzy objective function when considering the $k$ th objective, $\widetilde{c}_{i, j}^{(k)}$ denotes the fuzzy cost of acquiring $x_{j}$ from $x_{i}$ when considering the $k$ th objective, and $u_{i}$ denotes the subsidiary variable.

Thus, the fuzzy linear system (FLS) (refer Appendix B) can be formulated accordingly. Then, by assuming an equal weight of the three objectives, we can easily derive the result of the above optimal multiple criteria expansion process. Based on the fuzzy programming results, the technologies' expansion cost is 833 (refer Table 3), and the expansion route is as shown in Table 3 and Figure 4 . The expansion process route is $x_{0,2}, x_{0,5}$, and $x_{0,10}$ at stage 1 ; $x_{2,15}, x_{5,6}, x_{5,9}, x_{5,13}$, and $x_{10,12}$ at stage $2 ; x_{9,7}$ and $x_{12,11}$ at stage $3 ; x_{7,14}$ at stage $4 ; x_{14,3}$ at stage $5 ; x_{3,4}$ at stage $6 ; x_{4,8}$ at stage 7 ; and, finally, $x_{8,1}$ at stage 8 .

Table 3. Expansion process and costs of firm $X(u=0.5)$.

\begin{tabular}{cccccccc}
\hline \multicolumn{9}{c}{ Optimal Expansion Path } & & Cost \\
\hline $0 \rightarrow 2$ & $2 \rightarrow 15$ & $9 \rightarrow 7$ & $7 \rightarrow 14$ & $14 \rightarrow 3$ & $3 \rightarrow 4$ & $4 \rightarrow 8$ & $8 \rightarrow 1$ \\
$0 \rightarrow 5$ & $5 \rightarrow 6$ & $12 \rightarrow 11$ & & & & & \\
$0 \rightarrow 10$ & $5 \rightarrow 9$ & & & & & & 833.000 \\
& $5 \rightarrow 13$ & & & & & & \\
& $10 \rightarrow 12$ & & & & & & \\
\hline
\end{tabular}

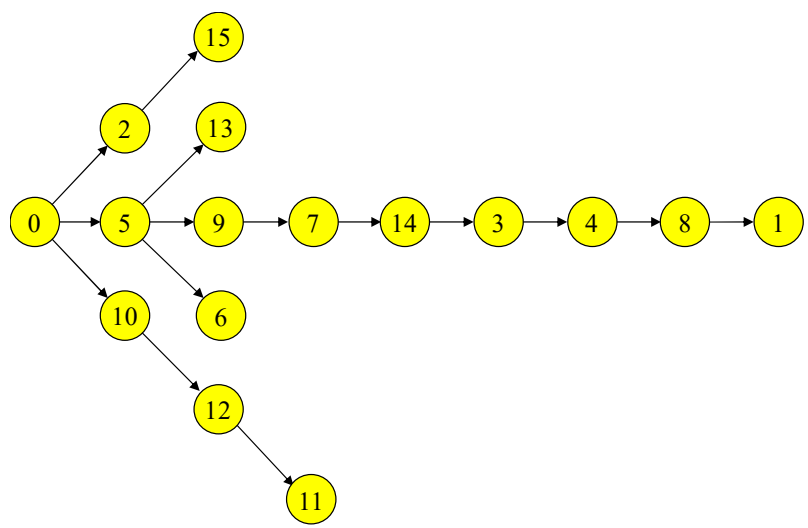

Figure 4. The minimum spanning tree for silicon intellectual property (SIP) development of design service company $X$.

4.3. Defining the Roadmap for SIPs Required for Future Application Specific Integrated Circuits of Unmanned Vehicles

Based on the minimum spanning tree derived in Section 4.3, the experts were invited again to decide on the suitable time slots for the initiation of each R\&D activity. Based on the experts' opinions, the starting time for developing each SIP can be determined. Then, the technology roadmap for SIP developments by the design service firm can be finalized, as shown in Figure 5. In the technology roadmap, ' 0 ' is the starting point for the competence set. Then, the competence sets $x_{8}$ and $x_{12}$ were expanded. After a season, the competence sets $x_{5}$ and $x_{11}$ were expanded. In the last quarter of 2020, the competence set $x_{2}$ was expanded. In the first quarter of 2021, three competence sets were expanded, $x_{3}, x_{9}$, and $x_{4}$. In the second quarter of 2021, two competence sets were expanded, $x_{6}$ and $x_{7}$. Finally, in the third quarter of 2021, three competence sets were expanded every two seasons: $x_{13}, x_{10}$, and $x_{1}$. 


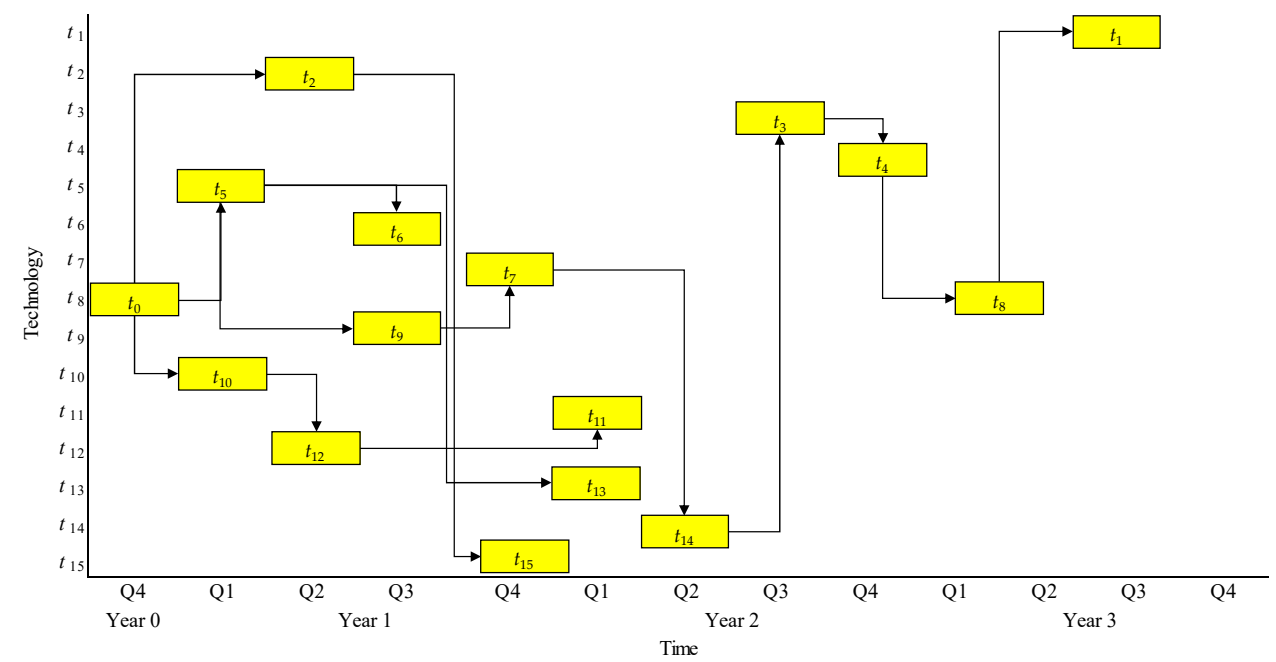

Figure 5. The roadmap of each expanding technology.

\subsection{Sensitivity Analysis}

According to [12], if the membership functions are different in form, the optimization problem cannot be resolved by using the linear parametric programming, so we must find an alternate method. This is fairly easy to do in reality since different values of the membership function can be experimented. That is, $\mu=0,0.1,0.2, \ldots, 1.0$. The corresponding linear programming problems can be solved. The results are shown in Table 4. 
Table 4. Expansion process and costs of firm $X(\mu=0.0,0.1, \ldots, 1.0)$.

\begin{tabular}{|c|c|c|c|c|c|c|c|c|c|c|c|c|c|c|c|c|c|c|}
\hline \multirow{2}{*}{$\begin{array}{c}\mathbf{u} \\
0.000\end{array}$} & \multicolumn{3}{|c|}{ Stage 1} & \multicolumn{3}{|c|}{ Stage 2} & \multicolumn{3}{|c|}{ Stage 3} & \multicolumn{3}{|c|}{ Stage 4} & \multirow[t]{2}{*}{ Stage 5} & \multirow[t]{2}{*}{ Stage 6} & \multirow[t]{2}{*}{ Stage 7} & \multirow[t]{2}{*}{ Stage 8} & \multirow[t]{2}{*}{ Stage 9} & \multirow{2}{*}{$\frac{\text { Cost }}{969.000}$} \\
\hline & 0 & $\rightarrow$ & 2 & 2 & $\rightarrow$ & 4 & 6 & $\rightarrow$ & 1 & 1 & $\rightarrow$ & 12 & & & & & & \\
\hline & 0 & $\rightarrow$ & 5 & 5 & $\rightarrow$ & 3 & & & & & & & & & & & & \\
\hline & 0 & $\rightarrow$ & 8 & 5 & $\rightarrow$ & 6 & & & & & & & & & & & & \\
\hline & 0 & $\rightarrow$ & 10 & 5 & $\rightarrow$ & 9 & & & & & & & & & & & & \\
\hline & 0 & $\rightarrow$ & 14 & 5 & $\rightarrow$ & 13 & & & & & & & & & & & & \\
\hline & & & & 8 & $\rightarrow$ & 7 & & & & & & & & & & & & \\
\hline & & & & 12 & $\rightarrow$ & 11 & & & & & & & & & & & & \\
\hline & & & & 12 & $\rightarrow$ & 15 & & & & & & & & & & & & \\
\hline \multirow[t]{9}{*}{0.100} & 0 & $\rightarrow$ & 2 & 2 & $\rightarrow$ & 4 & 1 & $\rightarrow$ & 12 & & & & & & & & & 944.100 \\
\hline & 0 & $\rightarrow$ & 5 & 5 & $\rightarrow$ & 3 & & & & & & & & & & & & \\
\hline & 0 & $\rightarrow$ & 8 & 5 & $\rightarrow$ & 6 & & & & & & & & & & & & \\
\hline & 0 & $\rightarrow$ & 10 & 5 & $\rightarrow$ & 9 & & & & & & & & & & & & \\
\hline & 0 & $\rightarrow$ & 14 & 5 & $\rightarrow$ & 13 & & & & & & & & & & & & \\
\hline & & & & 8 & $\rightarrow$ & 1 & & & & & & & & & & & & \\
\hline & & & & 8 & $\rightarrow$ & 7 & & & & & & & & & & & & \\
\hline & & & & 12 & $\rightarrow$ & 11 & & & & & & & & & & & & \\
\hline & & & & 12 & $\rightarrow$ & 15 & & & & & & & & & & & & \\
\hline \multirow[t]{9}{*}{0.200} & 0 & $\rightarrow$ & 2 & 2 & $\rightarrow$ & 4 & 1 & $\rightarrow$ & 12 & & & & & & & & & 919.200 \\
\hline & 0 & $\rightarrow$ & 5 & 5 & $\rightarrow$ & 3 & & & & & & & & & & & & \\
\hline & 0 & $\rightarrow$ & 8 & 5 & $\rightarrow$ & 6 & & & & & & & & & & & & \\
\hline & 0 & $\rightarrow$ & 10 & 5 & $\rightarrow$ & 9 & & & & & & & & & & & & \\
\hline & 0 & $\rightarrow$ & 14 & 5 & $\rightarrow$ & 13 & & & & & & & & & & & & \\
\hline & & & & 8 & $\rightarrow$ & 1 & & & & & & & & & & & & \\
\hline & & & & 8 & $\rightarrow$ & 7 & & & & & & & & & & & & \\
\hline & & & & 12 & $\rightarrow$ & 11 & & & & & & & & & & & & \\
\hline & & & & 12 & $\rightarrow$ & 15 & & & & & & & & & & & & \\
\hline \multirow[t]{6}{*}{0.300} & 0 & $\rightarrow$ & 2 & 2 & $\rightarrow$ & 15 & 3 & $\rightarrow$ & 4 & 12 & $\rightarrow$ & 11 & & & & & & 893.367 \\
\hline & 0 & $\rightarrow$ & 5 & 5 & $\rightarrow$ & 3 & 1 & $\rightarrow$ & 7 & & & & & & & & & \\
\hline & 0 & $\rightarrow$ & 8 & 5 & $\rightarrow$ & 6 & 1 & $\rightarrow$ & 12 & & & & & & & & & \\
\hline & 0 & $\rightarrow$ & 10 & 5 & $\rightarrow$ & 9 & & & & & & & & & & & & \\
\hline & 0 & $\rightarrow$ & 14 & 5 & $\rightarrow$ & 13 & & & & & & & & & & & & \\
\hline & & & & 8 & $\rightarrow$ & 1 & & & & & & & & & & & & \\
\hline
\end{tabular}


Table 4. Cont.

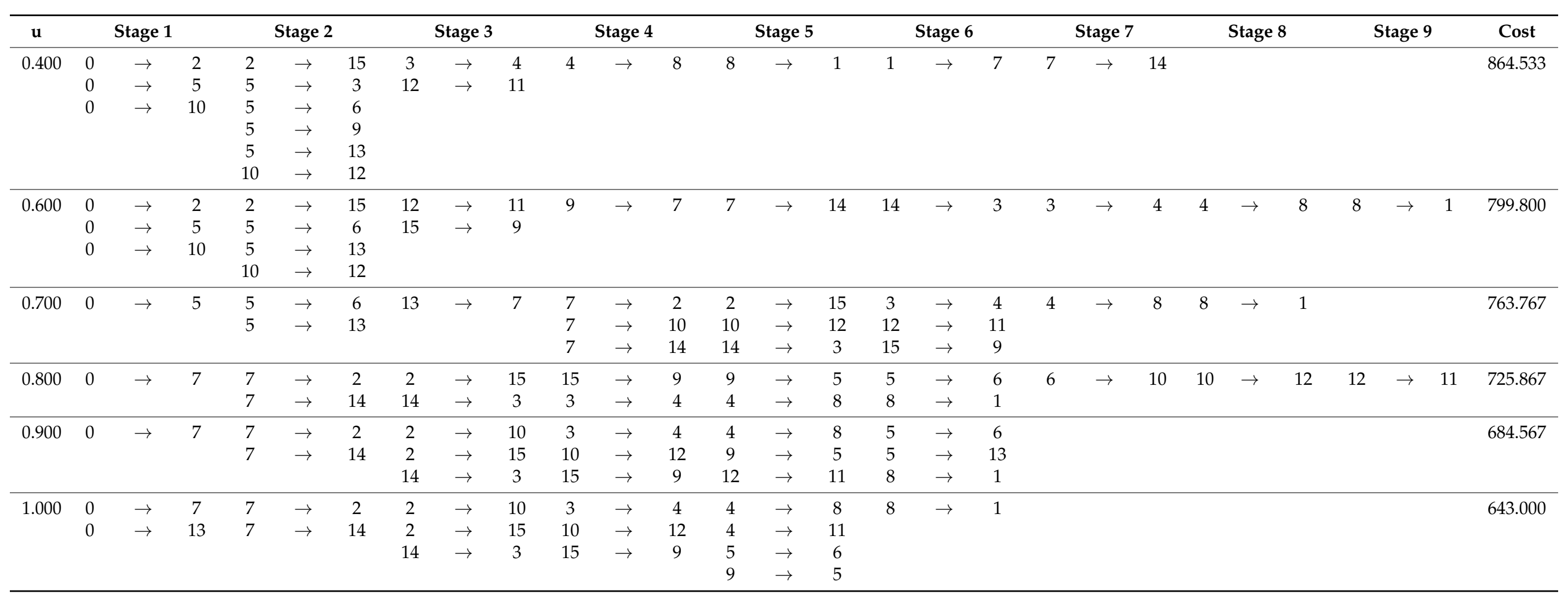




\section{Discussion}

The technology roadmap has been adopted by firms of the high-technology, manufacturing, service sectors, etc. as a vital tool for strategy definitions. Nevertheless, the issue of how roadmaps can be used to visualize the competence expansion processes for technology developments has seldom been discussed. In particular, the question of how fuzziness and uncertainties can be expressed by mathematical programming has rarely been addressed. In this work, we proposed an FMOP-based competence set expansion approach for developing technology roadmaps. The analytic framework has been verified as feasible based on an empirical case. In the future, the proposed FMOP-based analytic framework can be adopted by scholars and industry managers. The roadmapping framework can be combined with other types of analytic processes, especially the framework of technology mining. The analytic framework, containing both competence set expansion procedures and technology roadmapping results, will be extremely useful and helpful for high-technology firms. In this work, we proposed a novel technology roadmapping technique using an FMOP-based competence set expansion method. The proposed analytic framework improves the traditional roadmapping method and produces satisfactory results. In this section, the proposed programming technique will be discussed with respect to the advances in roadmapping techniques, the results of sensitivity analysis, strengths and weaknesses of the work, and future research possibilities.

\subsection{Advances in Roadmapping Techniques}

Since the introduction of the roadmapping technique by Motorola in the 1980s, it has been widely adopted by many high-technology firms worldwide. The roadmapping technique has also been disseminated to other industries. However, enhancing the performance of technology planning is particularly challenging. First, the problem of optimizing resource planning and utilization is always an NP-hard problem, which includes determining the number and sequence of new technologies to be explored and effectively allocating resources to R\&D activities [90]. Second, numerous types of uncertainties, e.g., the cost and duration of a project, are frequently involved because of ever-progressing technologies and the development of novel technologies, making R\&D costs and overtime expenses hard to forecast and control [90]. Although several research institutes or scholars have proposed roadmapping techniques using either quantitative or qualitative methods, few studies have proposed quantitative methods by considering multiple objective competence set expansion and uncertainties in real management practices. Examples include the well-known faststart T-Plan for technology roadmaps [50] proposed by scholars from Cambridge University, the text-mining-based quantitative approach by Choi et al. [91], and the integration of the quality function deployment and technology roadmaps [92]. Furthermore, some scholars adopted multicriteria decision-making methods such as the AHP [93] or integration of cross-impact analysis (CIA) and the AHP [94]. The abovementioned studies proposed qualitative methods, quantitative methods, or methods that hybridize both approaches. However, to our knowledge, no one has used an FMOP approach by incorporating the concept of competence set expansion.

Multiple objectives need to be considered in most management problems, particularly in R\&D management and technology management problems. The costs, performance, time-to-market, quality, and differentiation are the usual objectives in most management problems. Therefore, having to deal with multiple objectives in a technology roadmapping framework is a common situation. However, few scholars employed the MOP technique in roadmapping. According to Lai et al. [90], the extant literature focuses mainly on single research project management problems or on deterministic models. Therefore, our study advances the roadmapping technique and fills in a research gap.

Furthermore, previous studies on roadmaps seldom consider the concept of competence set expansion. However, technology roadmapping is by nature a projection of the competence set expansion theory onto roadmaps and R\&D management-that is, a high-technology firm can expand the acquired skill set $\left(t_{0}\right)$, or the set $(S k(E))$, to the 
true competence set $\left\{x_{0}, x_{1}, \ldots, x_{15}\right\}$, or the $(\operatorname{Tr}(E))$, as shown in Figure 1. In modern management research, competences play a dominant role, serving as the basis for strategic programming. According to Sanchez and Heene [95], the emphasis of conventional strategic theory on accumulating and controlling resources within, for example, a single firm offers limited understanding into modern product markets where extended networks of firms cooperate and compete concurrently. The competence perspective, on the other hand, has begun to offer insights into such phenomena by recognizing methods in which competitive advantage may be obtained through a superior capability to coordinate flows of intellectual properties and other resources within and between firms that function like open systems [95,96]. For example, Hill and Jones [97] have emphasized the importance of core competence in their works. According to Hill and Jones [97], competitive advantage is based upon the possession of distinctive competences. Distinctive competences are firm-specific strengths that enable a firm to differentiate its products from the ones being provided by competitors and/or achieve substantially lower costs than its rivals [97]. However, to our knowledge, no studies tried to link the concept of competence set expansion with roadmapping and R\&D strategy definitions. Thus, we advanced management theories and closed the research gap between research on roadmapping techniques and strategic management theories.

Third, with respect to uncertainties in technology roadmapping, real-world roadmapping, R\&D, and project management are full of uncertainties. According to Lai et al. [90], most existing studies consider the project planning problem in a deterministic framework in which all the parameters are supposed to be precisely known. However, in practice, uncertainty is usually involved in project planning, and critical parameters such as technical research duration, cost, and market demand can be highly uncertain. Recently, scholars have conducted research on integrating the concept of fuzziness into roadmapping. However, only a few scholars have attempted to integrate fuzziness into both MOP and roadmapping techniques. Most scholars adopted an analytic framework based on fuzzy multicriteria decision-making (e.g., the fuzzy cognitive map) in developing roadmaps. Thus, the present study advances traditional fuzzy roadmapping research by combining the FMOP technique and the competence set expansion theory.

\subsection{Discussion of the Results of Sensitivity Analysis}

Fourth, for the results of sensitivity analysis, we found that the expansion cost decreased from 969 (when $\mu=0$ ) to 643 (when $\mu=1$ ). This result was straightforward and can easily be explained by the first constraint of Equation (7), which is $-\left(A^{1}+\mu\left(A^{0}-A^{1}\right)\right) \boldsymbol{x} \leq \boldsymbol{b}^{1}+\mu\left(\boldsymbol{b}^{0}-\boldsymbol{b}^{1}\right)$. When $\mu=0$, only the upper bound of the interval was considered. In this case, the cost must be the highest. As the value of the membership function increases, the lower bound value of the interval function accounts for a higher portion. Thus, the parameters become lower as the membership function increases, and, thus, the total cost becomes lower. Finally, when $\mu=1$, the lower bound values account for the highest portion. Thus, the total expansion cost will be minimized.

\subsection{Strengths and Weaknesses of the Work}

This work is one of the earliest research projects to have solved the roadmapping problem by introducing the concept of FMOP. Thus, the research gaps mentioned in Section 2.4 were addressed. First, the work integrates the concepts of both competence set expansion and the FMOP technique into an analytic framework to solve the real-world problem. This process of integration addressed the research gap on the synthesis of the methods and then used it to solve the real-world strategic planning problem in general and the technology roadmapping problem specifically. Moreover, the work bridges the gap between technology roadmapping and FMOP. Many uncertainties exist in the development of new products, services, and techniques. The introduction of the concept of fuzziness is essential. Scholars and practitioners can introduce this analytic framework to solve the uncertainties and to address the fuzziness of their roadmapping problems. 
Regarding the weaknesses or limitations of this work, the intervals were introduced for the possible cost values associated with the parameters. In the future, triangular fuzzy numbers can also be applied to other aspects. Furthermore, the earliest and the latest start and finish times, which are usually considered during project management, were not involved in this work. Moreover, the study did not examine cases that consider multiple products (e.g., [84]) and have adopted the same technology. Finally, in this work, the competence set is assumed to be time-invariant, which is a special case in the changeable space theory mentioned by Larbani and Yu [24,25].

\subsection{Future Research Possibilities}

In the future, the proposed analytic technique can be integrated with the data mining results of academic research databases, patent libraries, etc. The text mining or patent mining results can serve as the basis for evaluating and selecting possible technology for a firm's future research. It would also be helpful to consider the earliest and latest start and finish times of each task. Furthermore, the time required for each task can also be included in the mathematical programming problem. Moreover, the assumptions of equal weight being associated with the objectives can also be removed. Methods like the Decision Making Trial and Evaluation Laboratory (DEMATEL)-based Analytic Network Process (ANP), or DANP $[98,99]$, can be adopted to derive the weights versus each objective. The technology roadmap can also be investigated by considering multiple products using the same technology. In the future, the technology roadmapping problem based on the time-varying competence set, which is more realistic, can be investigated further from the aspect of the changeable space theory [24,25]. For future research, the proposed analytic framework can be applied to the roadmapping of governments, industrial sectors, and private firms, irrespective of whether they are hardware or software industries.

\section{Conclusions}

Technology roadmaps have been widely adopted by national governments, research institutes, and firms in planning and coordinating the development of future projects. Although many scholars and managers have attempted to create analytic frameworks or methods for developing technology roadmaps, few scholars have proposed roadmaps using FMOP-based competence set expansion. However, an analytic framework with fuzzy mathematics, multiple objective decision-making, and the concept of competence set expansion is fully compatible with the nature of real-world R\&D and science and technology development projects. Thus, we proposed a programming technique based on FMOP and competence set expansion for developing technology roadmaps. An empirical study based on the planning of an SIP portfolio for developing a design platform for application specific integrated circuits to be adopted by unmanned vehicle vendors or integrated circuit design houses has demonstrated the feasibility of the proposed analytic framework. In the future, the well-verified analytic framework can be adopted by hightechnology firms or national governments for planning novel techniques with multiple objectives. In the future, triangular fuzzy numbers, the earliest and latest start and finish time of each task, and the time required for each task can also be included.

Author Contributions: C.-Y.H. designed, performed research, analyzed the data, wrote, and revised the paper. J.-J.H. advised on the research methods. Y.-N.C. and Y.-C.L. reviewed the papers and wrote portions of the literature review. All authors have read and agreed to the published version of the manuscript.

Funding: This article was subsidized by the Taiwan Normal University (NTNU), Taiwan and the Ministry of Science and Technology, Taiwan under Grant nos. MOST. 106-2221-E-003 -019 -MY3 and MOST. 109-2622-E-003-003-CC3.

Conflicts of Interest: The authors declare no conflict of interests. 


\section{Appendix A}

Table A1. Fuzzy costs for the objective $O_{1}$.

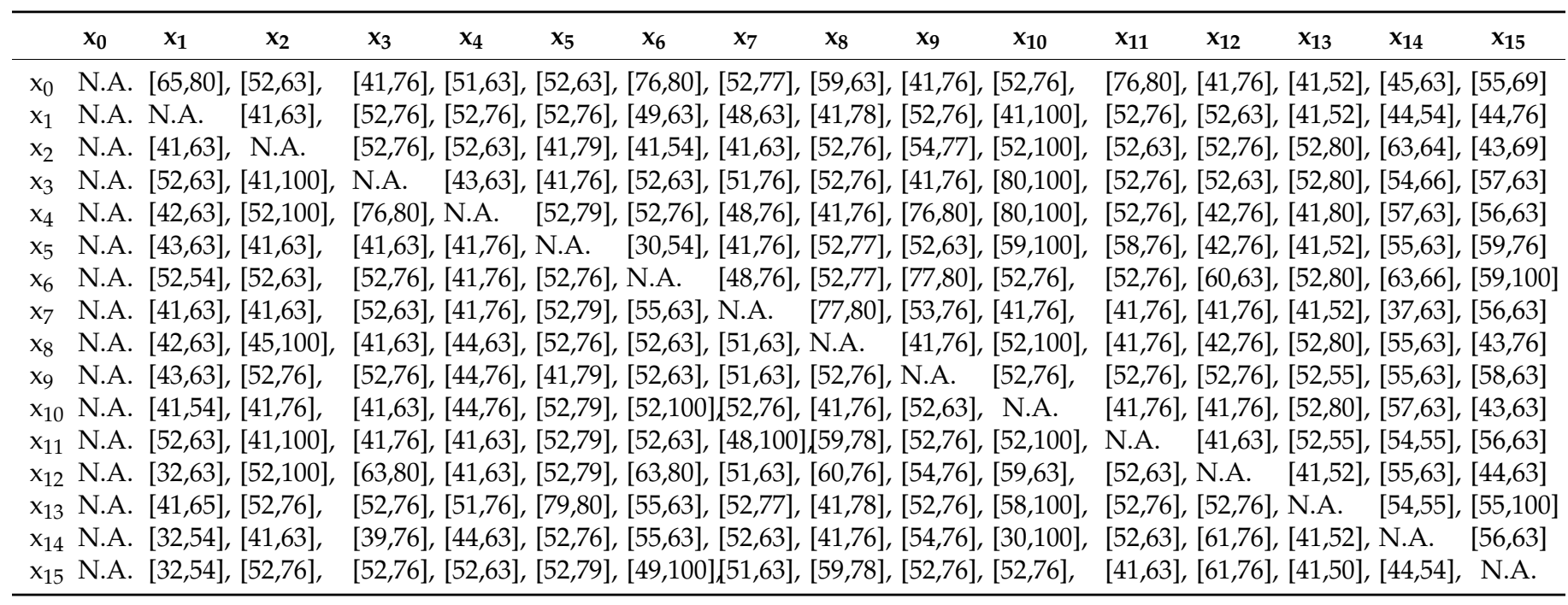

Remark: N.A. means not applicable.

Table A2. Fuzzy costs for the objective $\mathrm{O}_{2}$.

\begin{tabular}{|c|c|c|c|c|c|c|c|c|c|c|c|c|c|c|c|c|}
\hline & $\mathrm{x}_{0}$ & $x_{1}$ & $x_{2}$ & $x_{3}$ & $x_{4}$ & $x_{5}$ & $x_{6}$ & $x_{7}$ & $x_{8}$ & $X_{9}$ & $x_{10}$ & \multirow{2}{*}{\multicolumn{2}{|c|}{$\begin{array}{cc}\mathbf{x}_{\mathbf{1 1}} \quad \mathbf{x}_{\mathbf{1 2}} \\
{[41,76],[52,10}\end{array}$}} & $x_{13}$ & $x_{14}$ & $x_{15}$ \\
\hline $\mathrm{x}_{0}$ & N.A. & {$[41,63]$, } & $52,76]$, & {$[52,63$} & 43 & 41 & 41. & {$[41$} & 52 & {$\left[53,6^{3}\right.$} & , [58,76], & & & ]],41,5 & , $[54,5$ & {$[56,100]$} \\
\hline$x_{1}$ & N.A. & N.A. & {$[52,100]$} & {$[63,80]$} & {$[43,7$} & {$[41,7$} & {$[52,6$} & {$[51,77$} &,$[41,7$ & ],$[53,77$ & ],$[52,100]$ & {$[52,76$} &,$[52,6$ & ],$[52$, & ],$[54,57$ &,$[55,69]$ \\
\hline$x_{2}$ & N.A. & {$[52,63]$,} & N.A. & {$[52,76]$} &,$[52,63$ & {$[52,76$} & {$[55,76$} & {$[52,77$} &,$[78,80$ & ],$[52,77$ & ],$[30,100]$, & {$[41,76$} & ],$[52,7$ & ],$[41,52$ & ],$[63,64$ & {$[50,63]$} \\
\hline$x_{3}$ & N.A. & {$[54,80]$,} & {$[45,100]$,} & N.A. & {$[41,63$} & {$[79,80$} & {$[63,80$} & {$[52,6]$} & {$[52,7$} & {$[54,77$} & {$[52,100]$} & {$[41,76$} &,$[42,7$ &,$[64,8$ & {$[54,66$} & {$[63,68]$} \\
\hline$x_{4}$ & N.A. & {$[41,63]$, } & {$[45,76]$} & {$[76,80]$} & N.A. & {$[41,79$} & {$[41,63$} & {$[52,76$} & {$[52,78$} & ],$[76,80$ & ], $[52,100]$ & {$[41,76$} & ],$[52,76$ & ],$[52,6$ & ],$[50,63$ & {$[43,69]$} \\
\hline$x_{5}$ & N.A. & {$[43,65]$, } & {$[42,100]$,} & {$[52,63]$} & {$[63,80$} & N.A. & {$[52,63$} & {$[52,76$} & {$[76,80$} & ],$[41,63$ & , $[52,100]$ & {$[41,76$} & {$[52,76$} & ],$[52,60$ & ],$[57,63$ &,$[43,76]$ \\
\hline$x_{6}$ & N.A. & {$[41,63]$, } & {$[41,100]$} & {$[52,76]$} & {$[52,6$} & {$[41,79$} & N.A. & {$[52,76$} & {$[52,78$} & {$[77,80]$} & {$[41,76]$} & {$[52,63$} & ],$[52,7$ & ], $[64,8$ & {$[63,6$} & {$[44,63]$} \\
\hline$x_{7}$ & N.A. & {$[52,54]$,} & {$[41,100]$,} & {$[39,76$} & {$[44,7$} & {$[52,79$} & {$[49,63$} & N.A. & {$[77,80$} &,$[52,76$ & ],$[52,100]$, & {$[41,7$} & {$[52]$,} & {$[52$,} &,$[37,5$ & {$[43,63]$} \\
\hline $\mathrm{x}_{8}$ & N.A. & {$[30,54]$, } & {$[41,100]$,} & {$[76,80$} & {$[52,6$} & {$[52,7$} & {$[52,6$} & {$[51,76$} & N.A. & {$[52,76$} & ], $[80,100]$ & {$[41,7$} & , $[52$, & {$[52$} &,$[57$, & {$[66,100]$} \\
\hline$x_{9}$ & N.A. & {$[43,63]$, } & {$[42,63]$,} & {$[52,76]$} & {$[51,76$} & {$[41,10$} & , 63,80 & {$[52,76$} & {$[52,78$} & , N.A. & {$[52,76]$} & {$[52,76$} & ],$[52,76$ & {$[41,52$} &,$[45,63$ & {$[66,76]$} \\
\hline$x_{10}$ & N.A. & {$[42,63]$,} & {$[41,100]$,} & {$[52,76]$} & {$[41,6$} & {$[41,7$} & {$[63,8$} & {$[51,7]$} & {$[41,76$} &,$[53,77]$ & l, N.A. & {$[76,80$} & {$[52,63$} & ],$[41,52$ & {$[63,6$} & {$[66,100]$} \\
\hline $\mathrm{x}_{11}$ & N.A. & {$[41,63]$, } & {$[42,63]$} & {$[52,63]$} & {$[41,6$} & {$[41,7$} & 6 & {$[52,76$} & {$[52,7\}$} &,$[52,77$ & {$[59,100]$} & N.A. & {$[52,63$} & ],$[52,8$ & ],$[54,5$ & {$[57,76]$} \\
\hline$x_{12}$ & N.A. & {$[41,63]$, } & {$[42,100]$} & {$[63,80$} & {$[41,6$} & {$[52,7$} & {$[63,8$} & {$[51,7$} & {$[59,7$} & {$[54,6$} & {$[,[52,100]$} & {$[41,63$} & , N.A. & {$[52,80$} & {$[58,6$} & {$[58,63]$} \\
\hline$x_{13}$ & N.A. & {$[41,63]$, } & {$[41,76]$} & {$[41,63]$} & {$[41,76$} & {$[79,80$} & {$[54,80$} & {$[41,6$} & {$[41,7$} & {$[41,76$} & ], $[52,76]$ & {$[58,76$} & {$[41,7$} & , N.A. & {$[54,55$} & {$[57,63]$} \\
\hline$x_{14}$ & N.A. & {$[52,63]$,} & {$[63,80]$,} & {$[30,76]$} & {$[41,7$} & {$[52,7$} & {$[55,7$} & {$[52,7$} & {$[52,7$} & {$[41,76$} & {$[52,76]$} & {$[52,7$} & {$[76,8$} & {$[80,9$} & , N.A. & {$[59,100]$} \\
\hline $\mathrm{x}_{15}$ & N.A. & {$[42,63]$, } & {$[41,76]$,} & {$[53,63]$} & {$[43,76$} & {$[52,79$} & {$[52,63$} & {$[76,80$} &,$[52,76$ & {$[41,76$} & {$[,[52,100]$,} & {$[59,76$} & {$[52,63$} & ],$[40,50$ & ],$[45,54$ & , N.A. \\
\hline
\end{tabular}


Table A3. Fuzzy costs for the objective $\mathrm{O}_{3}$.

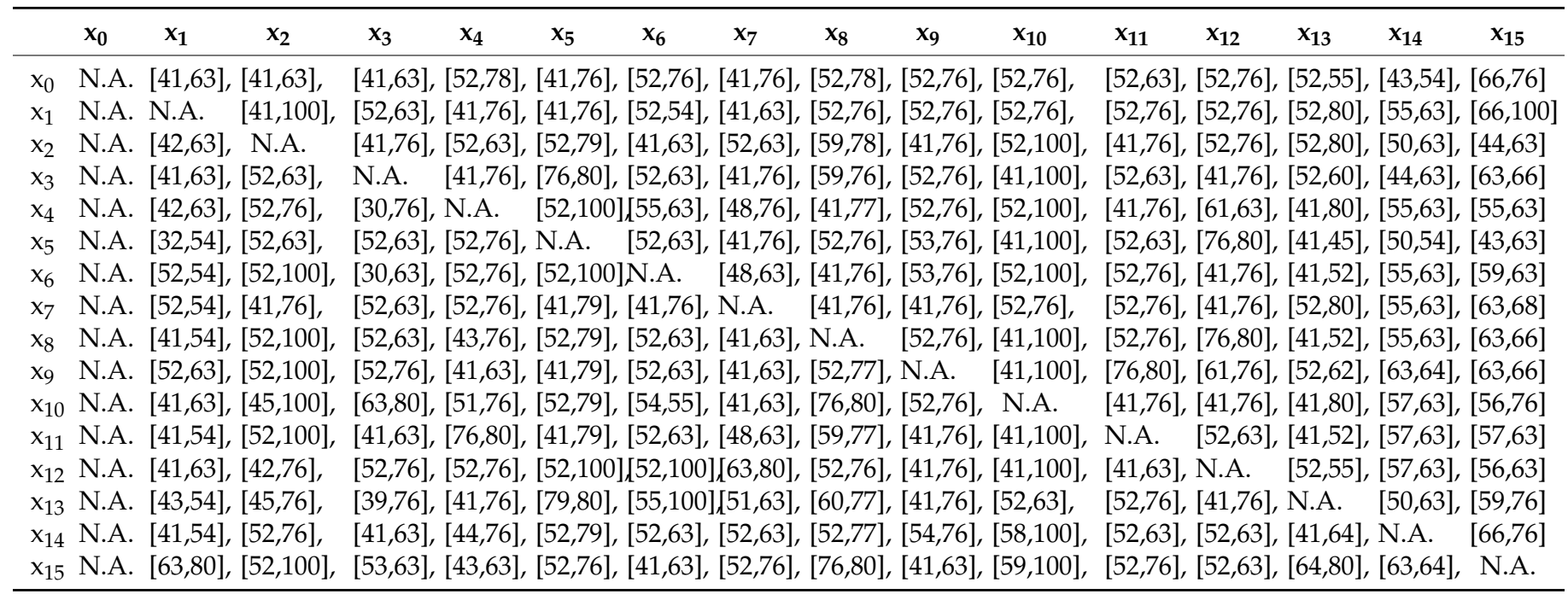

Remark: N.A. means not applicable.

\section{Appendix B}

The FLS 


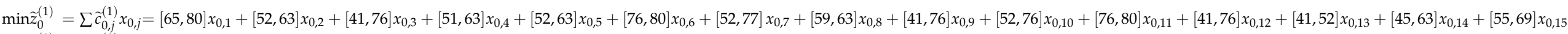
$\min \tilde{z}_{1}^{(1)}=\sum \widetilde{c}_{1, j}^{(1)} x_{1, j}=[52,76] x_{1,2}+[52,76] x_{1,3}+[52,76] x_{1,4}+[52,76] x_{1,5}+[49,63] x_{1,6}+[48,63] x_{1,7}+[41,78] x_{1,8}+[52,76] x_{1,9}+[41,100] x_{1,10}+[52,76] x_{1,11}+[52,63] x_{1,12}+[41,52] x_{1,13}+[44,54] x_{1,14}+[44,76] x_{1,15}$

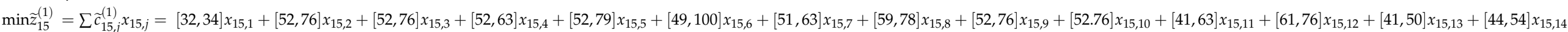

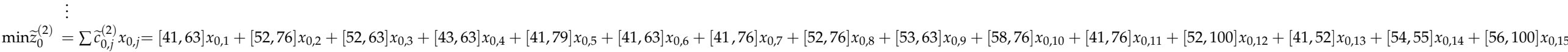

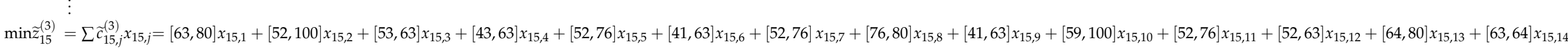

$x_{0,1}+x_{2,1}+x_{3,1}+x_{4,1}+x_{5,1}+x_{6,1}+x_{7,1}+x_{8,1}+x_{9,1}+x_{10,1}+x_{11,1}+x_{12,1}+x_{13,1}+x_{14,1}+x_{15,1}=1$ $x_{0,2}+x_{1,2}+x_{3,2}+x_{4,2}+x_{5,2}+x_{6,2}+x_{7,2}+x_{8,2}+x_{9,2}+x_{10,2}+x_{11,2}+x_{12,2}+x_{13,2}+x_{14,2}+x_{15,2}=1$

$x_{0,15}+x_{1,15}+x_{2,15}+x_{3,15}+x_{4,15}+x_{5,15}+x_{6,15}+x_{7,15}+x_{8,15}+x_{9,15}+x_{10,15}+x_{11,15}+x_{12,15}+x_{13,15}+x_{14,15}+x_{15,15}=1$

$u_{1}-u_{2}+16 x_{1,2}<=15$

$u_{1}-u_{3}+16 x_{1,3}<=15$

:

$u_{1}-u_{15}+16 x_{1,15}<=15$

$u_{15}-u_{1}+16 x_{15,1}<=15$

$u_{15}-u_{2}+16 x_{15,2}<=15$

$\vdots$

$u_{15}-u_{15}+16 x_{15,15}<=15$

$\forall x_{i, j}, u_{i} \in\{0,1, \ldots, 15\}$ 


\section{References}

1. Jeong, Y.; Yoon, B. Development of patent roadmap based on technology roadmap by analyzing patterns of patent development. Technovation 2015, 39, 37-52. [CrossRef]

2. Carvalho, M.M.; Fleury, A.; Lopes, A.P. An overview of the literature on technology roadmapping (trm): Contributions and trends. Technol. Forecast Soc. Chang. 2013, 80, 1418-1437. [CrossRef]

3. Phaal, R.; Farrukh, C.; Probert, D. Technology Roadmapping: Linking Technology Resources to Business Objectives; Centre for Technology Management, University of Cambridge: Cambridge, UK, 2001.

4. Gallegos, R.A.R.; Daim, T. Technology roadmap: Cattle farming sustainability in germany. J. Clean. Prod. 2016, 142, 4310-4326. [CrossRef]

5. Hamel, G.; Prahalad, C.K. The core competence of the corporation. Harv. Bus. Rev. 1990, 68, 79-91.

6. Van Kleef, J.A.; Roome, N. Developing capabilities and competence for sustainable business management as innovation: A research agenda. J. Clean. Prod. 2007, 15, 38-51. [CrossRef]

7. Po, L.Y.; Zhang, D. A foundation for competence set analysis. Math. Soc. Sci. 1990, 20, 251-299.

8. Yu, P.; Zhang, D. Optimal expansion of competence sets and decision support. INFOR 1992, 30, 68-84. [CrossRef]

9. Ghazinoory, S.; Daneshmand-Mehr, M.; Arasti, M.R. Developing a model for integrating decisions in technology roadmapping by fuzzy promethee. J. Intell. Fuzzy Syst. 2014, 26, 625-645. [CrossRef]

10. Hussain, M.; Tapinos, E.; Knight, L. Scenario-driven roadmapping for technology foresight. Technol. Forecast Soc. Chang. 2017, 124, 160-177. [CrossRef]

11. Siksnelyte-Butkiene, I.; Zavadskas, E.K.; Streimikiene, D. Multi-criteria decision-making (mcdm) for the assessment of renewable energy technologies in a household: A review. Energies 2020, 13, 1164. [CrossRef]

12. Carlsson, C.; Korhonen, P. A parametric approach to fuzzy linear programming. Fuzzy Sets Syst. 1986, 20, 17-30. [CrossRef]

13. Yu, P.-L. Habitual domains. Oper. Res. 1991, 39, 869-876. [CrossRef]

14. Chen, T.-Y. Using competence sets to analyze the consumer decision problem. Eur. J. Oper. Res. 2001, 128, 98-118. [CrossRef]

15. Yu, P.L. Forming Winning Strategies: An Integrated Theory of Habitual Domains; Springer: New York, NY, USA, 1990.

16. Zhan, Y.; Tan, K.H. An analytic infrastructure for harvesting big data to enhance supply chain performance. Eur. J. Oper. Res. 2020, 281, 559-574. [CrossRef]

17. Larbani, M.; Yu, P.-L. Competence set analysis, decision blinds and decision-making. In Wonderful Solutions and Habitual Domains for Challenging Problems in Changeable Spaces: From Theoretical Framework to Applications; Springer: Singapore, 2017 ; pp. 123-145.

18. Huang, J.-J.; Tzeng, G.-H.; Ong, C.-S. Optimal fuzzy multi-criteria expansion of competence sets using multi-objectives evolutionary algorithms. Expert Syst. Appl. 2006, 30, 739-745. [CrossRef]

19. Yu, P.-L.; Chen, Y.-C. Dynamic multiple criteria decision making in changeable spaces: From habitual domains to innovation dynamics. Ann. Oper. Res. 2012, 197, 201-220. [CrossRef]

20. Tsai, J.-F.; Wang, P.-C.; Lin, M.-H. Optimal expansion of competence sets with multilevel skills. Comput. Ind. Eng. 2012, 62, 770-776. [CrossRef]

21. Larbani, M.; Yu, P.L. Effective decision making in changeable spaces, covering and discovering processes: A habitual domain approach. In Human-Centric Decision-Making Models for Social Sciences; Springer: Berlin/Heidelberg, Germany, 2014; pp. 131-161.

22. Yu, P.; Chen, Y. Dynamic mcdm, habitual domains and competence set analysis for effective decision making in changeable spaces. In Trends in Multiple Criteria Decision Analysis; Greco, S., Ehrgott, M., Eds.; Springer: Boston, MA, USA, 2010 ; pp. 1-35.

23. Shi, Y.; Yu, P. Habitual domain analysis for effective decision making. In Multiple Criteria Decision Making and Risk Analysis Using Microcomputers; Karpak, B., Zionts, S., Eds.; Springer: New York, NY, USA, 1989; pp. 127-163.

24. Larbani, M.; Yu, P.L. Empowering data mining sciences by habitual domains theory, part I: The concept of wonderful solution. Ann. Data Sci. 2020, 7, 373-397. [CrossRef]

25. Larbani, M.; Yu, P.L. Empowering data mining sciences by habitual domains theory, part II: Reaching wonderful solutions. Ann. Data Sci. 2018, 7, 549-580. [CrossRef]

26. Çetindamar, D.; Phaal, R.; Probert, D. Technology Management: Activities and Tools; Palgrave Macmillan: New York, NY, USA, 2016.

27. Galvin, R. Science roadmaps. Science 1998, 280, 803. [CrossRef]

28. Galvin, R. Roadmapping-A practitioner's update. Technol. Forecast Soc. Chang. 2004, 71, 101-103. [CrossRef]

29. Harring, R. Motorola's use of the product technology roadmap. In Proceedings of the roceedings of the National Communications Forum, Rosemont, IL, USA, 24-26 September 1984; pp. 78-80.

30. Kostoff, R.N.; Schaller, R.R. Science and technology roadmaps. IEEE Trans. Eng. Manag. 2001, 48, 132-143. [CrossRef]

31. Cho, Y.; Yoon, S.-P.; Kim, K.-S. An industrial technology roadmap for supporting public r\&d planning. Technol. Forecast Soc. Chang. 2016, 107, 1-12.

32. Groenveld, P. Roadmapping integrates business and technology. Res. Technol. Manag. 1997, 40, 48-55. [CrossRef]

33. Yoon, B.; Phaal, R. Structuring technological information for technology roadmapping: Data mining approach. Technol. Anal. Strateg. Manag. 2013, 25, 1119-1137. [CrossRef]

34. Lee, J.H.; Phaal, R.; Lee, S.-H. An integrated service-device-technology roadmap for smart city development. Technol. Forecast Soc. Chang. 2013, 80, 286-306. [CrossRef] 
35. Garcia, M.L.; Bray, O.H. Fundamentals of Technology Roadmapping; Sandia National Labs.: Albuquerque, NM, USA, 1997.

36. Kappel, T.A. Perspectives on roadmaps: How organizations talk about the future. J. Prod. Innov. Manag. 2001, 18, 39-50. [CrossRef]

37. Wells, R.; Phaal, R.; Farrukh, C.; Probert, D. Technology roadmapping for a service organization. Res. Technol. Manag. 2004, 47, 46-51. [CrossRef]

38. Gerdsri, N.; Kocaoglu, D.F. Applying the analytic hierarchy process (AHP) to build a strategic framework for technology roadmapping. Math Comput. Model 2007, 46, 1071-1080. [CrossRef]

39. Moehrle, M.G.; Isenmann, R.; Phaal, R. Technology Roadmapping for Strategy and Innovation; Springer: Berlin/Heidelberg, Germany, 2013.

40. Phaal, R.; Farrukh, C.; Probert, D. A framework for supporting the management of technological innovation. In Proceedings of the Future of Innovation Studies Conference, Eindhoven, The Netherlands, 20-23 September 2001.

41. Lee, S.; Park, Y. Customization of technology roadmaps according to roadmapping purposes: Overall process and detailed modules. Technol. Forecast Soc. Chang. 2005, 72, 567-583. [CrossRef]

42. Saad, S.; Perera, T.; Gindy, N.N.; Cerit, B.; Hodgson, A. Technology roadmapping for the next generation manufacturing enterprise. J. Manuf. Technol. Manag. 2006, 17, 404-416.

43. Lee, J.H.; Kim, H.-I.; Phaal, R. An analysis of factors improving technology roadmap credibility: A communications theory assessment of roadmapping processes. Technol. Forecast Soc. Chang. 2012, 79, 263-280. [CrossRef]

44. Son, W.; Lee, S. Integrating fuzzy-set theory into technology roadmap development to support decision-making. Technol. Anal. Strateg. Manag. 2019, 31, 447-461. [CrossRef]

45. Lee, J.H.; Phaal, R.; Lee, C. An empirical analysis of the determinants of technology roadmap utilization. $R D$ Manag. 2011, 41, 485-508. [CrossRef]

46. Yoon, B.; Phaal, R.; Probert, D. Morphology analysis for technology roadmapping: Application of text mining. $R$ D Manag. 2008, 38, 51-68. [CrossRef]

47. Trappey, A.J.; Trappey, C.V.; Fan, C.-Y.; Hsu, A.P.; Li, X.-K.; Lee, I.J. IoT patent roadmap for smart logistic service provision in the context of industry 4.0. J. Chin. Inst. Eng. 2017, 40, 593-602. [CrossRef]

48. Bray, O.H.; Garcia, M.L. Technology roadmapping: The integration of strategic and technology planning for competitiveness. In Proceedings of the Portland International Conference on Management of Engineering and Technology (PICMET), Portland, OR, USA, 31 July 1997.

49. Institute for Manufacturing. T-Plan: The Fast Start to Technology Roadmapping: Planning Your Route to Success; University of Cambridge: Cambridge, UK, 2001.

50. Holmes, C.; Ferrill, M. The application of operation and technology roadmapping to aid singaporean smes identify and select emerging technologies. Technol. Forecast Soc. Chang. 2005, 72, 349-357. [CrossRef]

51. Martin, G.; Eggink, E. Creation of a thermal technology roadmap in a consumer electronics product environment. In Proceedings of the Twenty-fourth Annual IEEE Semiconductor Thermal Measurement and Management Symposium (Semi-Therm), San Jose, CA, USA, 16-20 March 2008.

52. Kim, H.Y.; Park, Y.T. Development and Application of Web-Based Technology Roadmap: QFD and Scenario Planning Approach. In Proceedings of Proceedings of the 2004 Fall Conference of Korean Society of Industrial Engineers, Seoul, South Korea, 12-13 November 2004.

53. Lee, C.; Lee, J. Conjoint analysis and qfd for a reliable starting point of technology roadmap. J. Technol. Innov. 2007, 16, 65-86.

54. Phaal, R.; Muller, G. An architectural framework for roadmapping: Towards visual strategy. Technol. Forecast Soc. Chang. 2009, 76, 39-49. [CrossRef]

55. European Industrial Research Management Association. Technology Roadmapping: Delivering Business Vision, Working Group Reports; European Industrial Research Management Association: Bruxelles, Belgium, 1997.

56. Daim, T.U.; Amer, M.; Brenden, R. Technology roadmapping for wind energy: Case of the pacific northwest. J. Clean. Prod. 2012, 20, 27-37. [CrossRef]

57. Hansen, C.; Daim, T.; Ernst, H.; Herstatt, C. The future of rail automation: A scenario-based technology roadmap for the rail automation market. Technol. Forecast Soc. Chang. 2016, 110, 196-212. [CrossRef]

58. Lee, S.; Lee, S.; Seol, H.; Park, Y. Using patent information for designing new product and technology: Keyword based technology roadmapping. $R$ D Manag. 2008, 38, 169-188. [CrossRef]

59. Beeton, D. Exploratory Roadmapping for Sector Foresight; University of Cambridge: Cambridge, UK, 2007.

60. Tzeng, G.-H.; Huang, J.-J. Fuzzy Multiple Objective Decision Making; CRC Press: Boca Raton, FL, USA, 2014.

61. Kuhn, H.W.; Tucker, A. Nonlinear Programming Proceedings of the Second Berkeley Symposium on Mathematical Statistics and Probability; Neyman, J., Ed.; University of California Press: Berkeley, CA, USA, 1951.

62. Yu, P.-L. A class of solutions for group decision problems. Manag. Sci. 1973, 19, 936-946. [CrossRef]

63. Bellman, R.E.; Zadeh, L.A. Decision-making in a fuzzy environment. Manag. Sci. 1970, 17, 141-164. [CrossRef]

64. Hwang, C.L.; Yoon, K. Multiple Attribute Decision Making: Methods and Applications—A State-of-the-Art Survey; Springer: Berlin/Heidelberg, Germany, 1981.

65. Zimmermann, H.-J. Fuzzy programming and linear programming with several objective functions. Fuzzy Sets Syst. 1978, 1, 45-55. [CrossRef] 
66. Sakawa, M. Fuzzy Sets and Interactive Multiobjective Optimization; Plenum: New York, NY, USA, 2013.

67. Lee, E.S.; Li, R.J. Fuzzy multiple objective programming and compromise programming with pareto optimum. Fuzzy Sets Syst. $1993,53,275-288$.

68. Atteya, T.E.M. Rough multiple objective programming. Eur. J. Oper. Res. 2016, 248, 204-210. [CrossRef]

69. Holzmann, T.; Smith, J.C. Solving discrete multi-objective optimization problems using modified augmented weighted tchebychev scalarizations. Eur. J. Oper. Res. 2018, 271, 436-449. [CrossRef]

70. Botte, M.; Schöbel, A. Dominance for multi-objective robust optimization concepts. Eur. J. Oper. Res. 2019, 273, 430-440. [CrossRef]

71. Chung, C.-K.; Chen, H.M.; Chang, C.-T.; Huang, H.-L. On fuzzy multiple objective linear programming problems. Expert Syst. Appl. 2018, 114, 552-562. [CrossRef]

72. Roy, A.; Manna, A.; Maity, S. A novel memetic genetic algorithm for solving traveling salesman problem based on multi-parent crossover technique. Decis. Mak. App. Manag. Eng. 2019, 2, 100-111. [CrossRef]

73. Biswas, P.; Pal, B.B. A fuzzy goal programming method to solve congestion management problem using genetic algorithm. Decis. Mak. App. Manag. Eng. 2019, 2, 36-53. [CrossRef]

74. Ganguly, S. Multi-objective distributed generation penetration planning with load model using particle swarm optimization. Decis. Mak. App. Manag. Eng. 2020, 3, 30-42. [CrossRef]

75. Borovička, A. New complex fuzzy multiple objective programming procedure for a portfolio making under uncertainty. Appl. Soft Comput. 2020, 96, 106607. [CrossRef]

76. Koronakos, G.; Smirlis, Y.; Sotiros, D.; Despotis, D.K. Assessment of oecd better life index by incorporating public opinion. Socio Econ. Plan. Sci. 2020, 70, 100699. [CrossRef]

77. Tavana, M.; Khalili-Damghani, K.; Arteaga, F.J.S.; Hosseini, A. A fuzzy multi-objective multi-period network dea model for efficiency measurement in oil refineries. Comput. Ind. Eng. 2019, 135, 143-155. [CrossRef]

78. Kouaissah, N.; Hocine, A. Optimizing sustainable and renewable energy portfolios using a fuzzy interval goal programming approach. Comput. Ind. Eng. 2020, 144, 106448. [CrossRef]

79. Chen, N.-S.; Huang, H.-Y.; Shih, Y.-C. Factors affecting usage of web-based teachers' training in elementary and high school. In Proceedings of the International Conference on Computers in Education, Auckland, New Zealand, 3-6 December 2002.

80. Li, T.; Tong, S.; Zhang, H. Transparency of information acquisition in a supply chain. Manuf. Serv. Oper. Manag. 2014, 16, 412-424. [CrossRef]

81. Mishra, A.A.; Shah, R. In union lies strength: Collaborative competence in new product development and its performance effects. J. Oper. Manag. 2009, 27, 324-338. [CrossRef]

82. Schmenner, R.W.; Vastag, G. Revisiting the theory of production competence: Extensions and cross-validations. J. Oper. Manag. 2006, 24, 893-909. [CrossRef]

83. Tan, K.H.; Zhan, Y.; Ji, G.; Ye, F.; Chang, C. Harvesting big data to enhance supply chain innovation capabilities: An analytic infrastructure based on deduction graph. Int. J. Prod. Econ. 2015, 165, 223-233. [CrossRef]

84. Dalkey, N.; Helmer, O. An experimental application of the Delphi method to the use of experts. Manag. Sci. 1963, 9, 458-467. [CrossRef]

85. Murry, J.W.; Hammons, J.O. Delphi: A versatile methodology for conducting qualitative research. Rev. High Ed. 1995, 18, 423-436. [CrossRef]

86. Brooks, K.W. Delphi technique: Expanding applications. N. Ctr. Assoc. Qtly. 1979, 54, 377-385.

87. Shi, D.; Yu, P. Optimal expansion and design of competence sets with asymmetric acquiring costs. J. Optim Theory Appl. 1996, 88, 643-658. [CrossRef]

88. Lee, S. Linking technology roadmapping to patent analysis. In Technology Roadmapping for Strategy and Innovation; Springer: New York, NY, USA, 2013; pp. 267-284.

89. Bagloee, S.A.; Tavana, M.; Asadi, M.; Oliver, T. Autonomous vehicles: Challenges, opportunities, and future implications for transportation policies. J. Mod. Transp. 2016, 24, 284-303. [CrossRef]

90. Lai, C.; Xu, L.; Shang, J. Optimal planning of technology roadmap under uncertainty. J. Oper. Res. Soc. 2020, 71, 673-686. [CrossRef]

91. Choi, S.; Kim, H.; Yoon, J.; Kim, K.; Lee, J.Y. An sao-based text-mining approach for technology roadmapping using patent information. $R$ D Manag. 2013, 43, 52-74. [CrossRef]

92. An, Y.; Lee, S.; Park, Y. Development of an integrated product-service roadmap with qfd. Int. J. Serv. Manag. 2008, 19, 621-638. [CrossRef]

93. Gerdsri, N.; Vatananan, R.S. Dynamics of technology roadmapping (TRM) implementation. In Proceedings of the PICMET'07-2007 Portland International Conference on Management of Engineering \& Technology, Portland, OR, USA, 5-9 August 2007.

94. Lee, H.; Geum, Y. Development of the scenario-based technology roadmap considering layer heterogeneity: An approach using cia and ahp. Technol. Forecast Soc. Chang. 2017, 117, 12-24. [CrossRef]

95. Sanchez, R.; Heene, A. Reinventing strategic management: New theory and practice for competence-based competition. Eur. Manag. J. 1997, 15, 303-317. [CrossRef]

96. Sanchez, R. Strategic product creation: Managing new interactions of technology, markets, and organizations. Eur. Manag. J. 1996, 14, 121-138. [CrossRef] 
97. Hill, C.W.L.; Schilling, M.A.; Jones, G.R. Strategic Management Theory: An Integrated Approach, 13th ed.; Cengage Learning: Boston, MA, USA, 2019.

98. Liu, C.-H.; Tzeng, G.-H.; Lee, M.-H. Improving tourism policy implementation-the use of hybrid mcdm models. Tour. Manag. 2012, 33, 413-426. [CrossRef]

99. Phillips-Wren, G.; Jain, L.C.; Nakamatsu, K.; Howlett, R.J. Advances in Intelligent Decision Technologies. In Proceedings of the Second KES International Symposium IDT 2010, Baltimore, MD, USA, 28-30 July 2010; Springer: Berlin/Heidelberg, Germany, 2010. 